\title{
əFuture Changes and Controlling Factors of the Eight Regional Monsoons Projected by CMIP6 Models
}

\author{
Chunhan Jin \\ Key Laboratory for Virtual Geographic Environment, Ministry of Education, State Key Laboratory Cultivation Base of \\ Geographical Environment Evolution of Jiangsu Province, Jiangsu Center for Collaborative Innovation in Geographical \\ Information Resource Development and Application, School of Geography Science, Nanjing Normal University, Nanjing, China

\begin{abstract}
BIN WANG
Department of Atmospheric Sciences, University of Hawai'i at Mānoa, Honolulu, Hawaii, and Earth System Modeling Center, Nanjing University of Information Science and Technology, Nanjing, China
\end{abstract} \\ JIAN LIU \\ Key Laboratory for Virtual Geographic Environment, Ministry of Education, State Key Laboratory Cultivation Base of \\ Geographical Environment Evolution of Jiangsu Province, Jiangsu Center for Collaborative Innovation in Geographical \\ Information Resource Development and Application, School of Geography Science, and Jiangsu Provincial Key Laboratory \\ for Numerical Simulation of Large Scale Complex Systems, School of Mathematical Science, Nanjing Normal University, \\ Nanjing, China
}

(Manuscript received 7 April 2020, in final form 10 August 2020)

\begin{abstract}
An accurate prediction of land monsoon precipitation (LMP) is critical for the sustainable future of the planet as it provides water resources for more than two-thirds of the global population. Here, we show that the ensemble mean of 24 CMIP6 (phase 6 of the Coupled Model Intercomparison Project) models projects that, under the Shared Socioeconomic Pathway 2-4.5 (SSP2-4.5) scenario, summer LMP will very likely increase in South Asia $\left(\sim 4.1 \%{ }^{\circ} \mathrm{C}^{-1}\right)$, likely increase in East Asia $\left(\sim 4.6 \%{ }^{\circ} \mathrm{C}^{-1}\right)$ and northern Africa $\left(\sim 2.9 \%{ }^{\circ} \mathrm{C}^{-1}\right)$, and likely decrease in North America $\left(\sim-2.3 \%{ }^{\circ} \mathrm{C}^{-1}\right)$. The annual mean LMP in three Southern Hemisphere monsoon regions will likely remain unchanged due to significantly decreased winter precipitation. Regional mean LMP changes are dominated by the change in upward moisture transport with moderate contribution from evaporation and can be approximated by the changes of the product of the midtropospheric ascent and $850-\mathrm{hPa}$ specific humidity. Greenhouse gas (GHG)-induced thermodynamic effects increase moisture content and stabilize the atmosphere, tending to offset each other. The spatially uniform increase of humidity cannot explain markedly different regional LMP changes. Intermodel spread analysis demonstrates that the GHGinduced circulation changes (dynamic effects) are primarily responsible for the regional differences. The GHGs induce a warm land-cool ocean pattern that strengthens the Asian monsoon, and a warm North Atlantic and Sahara that enhances the northern African monsoon, as well as an equatorial central Pacific warming that weakens the North American monsoon. CMIP6 models generally capture realistic monsoon rainfall climatology, but commonly overproduce summer rainfall variability. The models' biases in projected regional SST and land-sea thermal contrast likely contribute to the models' uncertainties in the projected monsoon rainfall changes.
\end{abstract}

KEYWORDS: Land surface; Dynamics; Vertical motion; Monsoons; Climate change; Coupled models

\section{Introduction}

The global monsoon is the dominant mode of annual variation of the tropical-subtropical precipitation and circulation, and thus a defining feature and a primary mode of variability of Earth's climate (Wang and Ding 2008). However, monsoons vary considerably from region to region, and each regional monsoon has unique features due to its specific land-ocean and topographic configuration, different remote forcings, and atmosphere-ocean-land interaction processes. It is the regional monsoon (RM) manifestation that directly affects people, and therefore understanding their

¿ Denotes content that is immediately available upon publication as open access.

Corresponding author: Jian Liu, jliu@njnu.edu.cn variability, predictability, and future change are of fundamental societal and scientific importance.

Future changes of the regional monsoon projected by phase 5 of the Coupled Model Intercomparison Project (CMIP5) models have been broadly explored. The South Asia (SA) summer monsoon rainfall was consistently projected to increase (Menon et al. 2013; Sharmila et al. 2015; Kitoh et al. 2013), and the precipitation sensitivity (percentage change scaled to one degree Celsius of global warming) is about $5.0 \%{ }^{\circ} \mathrm{C}^{-1}$ (Wang et al. 2014), although some models suggest the rainy season would shorten (Sabeerali and Ajayamohan 2018). East Asian (EA) summer monsoon rainfall was projected to increase by $6.4 \%{ }^{\circ} \mathrm{C}^{-1}$ (Wang et al. 2014), while the duration of the EA rainy season may be lengthened due to advanced onset and delayed retreat (Kitoh et al. 2013; Moon and Ha 2017). The projected entire Asian-Australian monsoon low-level circulation 
tends to weaken significantly (by $\sim 2.3 \%{ }^{\circ} \mathrm{C}^{-1}$ ) due to atmospheric stabilization, but the EA subtropical monsoon circulation increases by $\sim 4.4 \%{ }^{\circ} \mathrm{C}^{-1}$. In addition, the Asian monsoon domain over the land area is projected to expand by about $10 \%$ (Wang et al. 2014). The projected northern African (NAF) monsoon generally gets a wetter late season (except for the west coast) and delayed cessation of the rains (Biasutti 2013; Roehrig et al. 2013). For the North American (NAM) monsoon, climate model projections suggest an early-to-late redistribution and unchanged mean precipitation in the traditional NAM region (Cook and Seager 2013), but a substantial reduction for Central American precipitation (Colorado-Ruiz et al. 2018). Nevertheless, there is low confidence in the NAM projections as large uncertainties are involved (Bukovsky et al. 2015; Meyer and Jin 2017; Pascale et al. 2017).

Southern Hemisphere ( $\mathrm{SH})$ monsoon changes are different from those in the Northern Hemisphere $(\mathrm{NH})$ due to the hemispheric differential warming induced by the anthropogenic forcing and land-ocean configuration (Wang et al. 2014). In the Australian-Indonesian monsoon region, most "good" CMIP5 models project a $5 \%-20 \%$ increase in monsoon rainfall over the northern (north of $20^{\circ} \mathrm{S}$ ) Australian (AUS) region during the latter part of the twenty-first century, while increasing trends over the Maritime Continent have more uncertainty (Jourdain et al. 2013), which seems to be consistent with the moderate increase in the total Australian-Indonesian monsoon precipitation by $2.6 \%{ }^{\circ} \mathrm{C}^{-1}$ (Wang et al. 2014). Models project that there are no significant changes in the duration and average rainfall over the southern African (SAF) region, although both the onset and retreat would be delayed (Kitoh et al. 2013). The South American (SAM) precipitation projected by CMIP5 shows little change in the total precipitation, but a delay and shortening of the monsoon season (Seth et al. 2013). However, Jones and Carvalho (2013) suggested that most of the CMIP5 models project early onsets, late demises, and lengthening duration of the SAM. The intermodel discrepancies are large (Yin et al. 2013), and the bias-corrected projections generally show a drier climate over eastern Amazonia (Duffy et al. 2015; Malhi et al. 2008).

Although the future RM changes have been widely explored, it is still of great difficulty to compare and synthesize the results in regional monsoon projections provided by different authors because the results were often obtained using different definitions of monsoon domains and different metrics (variables and criteria) for evaluation and projection, which depend on authors' research interests and perspectives. Wang et al. (2020b) have assessed and explored the future changes of global monsoon by using 15 models that participated in phase 6 of the Coupled Model Intercomparison Project (CMIP6) projects, under the Shared Socioeconomic Pathway 2-4.5 (SSP2-4.5). The projected NH total land monsoon precipitation (LMP) likely increases by about $2.8 \%$ per degree of global warming $\left(2.8 \%{ }^{\circ} \mathrm{C}^{-1}\right)$, which contrasts with the little change in the $\mathrm{SH}\left(-0.3 \%{ }^{\circ} \mathrm{C}^{-1}\right)$. While the specific humidity increase is nearly uniform in all summer monsoon regions, the LMP changes vary considerably from region to region. Thereby, the following sequential questions arise: 1) What are the differences in the projected LMP changes among eight monsoon regions? 2) What hydroclimate factors contribute to the regional LMP changes? 3) How does the GHG forcing cause the regional monsoon circulation and precipitation changes? These questions motivate the present study. In this study, we objectively define regional monsoon rainfall domains using uniform criteria and apply the same metrics to all regional monsoons to better identify the differences in projected future changes among various monsoon regions. This approach facilitates investigation of the models' common biases and sources of uncertainties, and helps to track the progress made across the CMIP series of experiments in the past and future. We will particularly focus on the LMP as it profoundly influences the regional water supply and economic development.

The present study uses multiple ensemble members from 24 CMIP6 CGCMs (Eyring et al. 2016) to assess models' performance and common biases in simulating historical climate and the potential future changes of LMP in the twenty-first century, and to understand the underlying causes and sources of projection uncertainties. Section 2 describes observational data, model simulations, and analysis methods. In section 3, we evaluate historical simulations against the observation for the period of 1979-2014. Section 4 presents the projected future changes in regional monsoons. Section 5 discusses the critical processes controlling future changes of the regional LMP and the causes of the projected uncertainties. The last section presents a summary.

\section{Data and method}

\section{a. Observational datasets and CMIP6 models' results}

Observational datasets used include the monthly precipitation data compiled by the Global Precipitation Climatology Project (GPCP), v2.3 (Adler et al. 2003), the monthly mean sea surface temperature (SST) data are obtained from the Hadley Centre Sea Ice and Sea Surface Temperature (HadISST) (Rayner et al. 2003), and the National Oceanic and Atmospheric Administration Extended Reconstructed SST (ERSST) version 5 (Huang et al. 2017). The circulation data are obtained from the ERA-Interim reanalysis dataset (Dee et al. 2011). To reduce the uncertainty in each SST dataset, we have made a "merged" monthly mean SST dataset by simply taking their arithmetic means.

To evaluate models' performance and to lay a baseline for assessing future changes, the historical experiments (HIST) derived from 24 CMIP6 CGCMs were used. Table 1 lists the models' basic information. Since the CMIP6 models have more ensemble simulations for the historical run than the SSP2-4.5 run, we have used the same number of ensemble members for the two experiments. To assess future climate change, we analyzed the data for the period of 2015-2100 derived from the climate projections under SSP2-4.5 in the CMIP6 archive (O'Neill et al. 2016). The SSP24.5 scenario is an updated version of the representative concentration pathway 4.5 (RCP4.5) of CMIP5; it assumes a medium level of greenhouse gas emission and that the radiative forcing will stabilize at about $4.5 \mathrm{~W} \mathrm{~m}^{-2}$ in 2100 . The land use and aerosol pathways specified in RCP2-4.5 were combined with an intermediate level of societal vulnerability (O'Neill et al. 2016).

For a fair comparison, all observed data and models' output were interpolated to the $2.5^{\circ}$ latitude $\times 2.5^{\circ}$ longitude grid. The 
TABLE 1. Description of CMIP6 models used in the present study.

\begin{tabular}{|c|c|c|c|}
\hline Model acronym & Institution & Atmosphere resolution lat $\times$ lon & Ensemble No. \\
\hline ACCESS-ESM1-5 & $\begin{array}{l}\text { Australian Community Climate and Earth } \\
\text { System Simulator (ACCESS) }\end{array}$ & $145 \times 192$ & 3 \\
\hline BCC-CSM2-MR & $\begin{array}{l}\text { Beijing Climate Center, China } \\
\text { Meteorological Administration (BCC) }\end{array}$ & $160 \times 320$ & 1 \\
\hline CanESM5 & $\begin{array}{l}\text { Canadian Centre for Climate Modeling } \\
\text { and Analysis (CCCma) }\end{array}$ & $64 \times 128$ & 3 \\
\hline CESM2 & National Center for Atmospheric & $192 \times 288$ & 3 \\
\hline CESM2-WACCM & Research (NCAR) & $192 \times 288$ & 3 \\
\hline CNRM-CM6-1 & Centre National de Recherches & $128 \times 256$ & 3 \\
\hline CNRM-ESM2-1 & $\begin{array}{l}\text { Meteorologiques/Centre Europeen de } \\
\text { Recherche et Formation Avancees en } \\
\text { Calcul Scientifique } \\
\text { (CNRMCERFACS) }\end{array}$ & $128 \times 256$ & 3 \\
\hline EC-Earth3-Veg & EC-Earth-Consortium & $256 \times 512$ & 3 \\
\hline FGOALS-g3 & Chinese Academy of Sciences (CAS) & $80 \times 180$ & 1 \\
\hline FIO-ESM-2-0 & $\begin{array}{l}\text { First Institute of Oceanography, Ministry } \\
\text { of Natural Resources (FIO) }\end{array}$ & $192 \times 288$ & 3 \\
\hline GFDL-CM4 & Geophysical Fluid Dynamics Laboratory & $180 \times 288$ & 1 \\
\hline GFDL-ESM4 & (NOAA GFDL) & $180 \times 288$ & 3 \\
\hline HadGEM3-GC31-LL & Met Office Hadley Centre (MOHC) & $144 \times 192$ & 1 \\
\hline INM-CM5-0 & $\begin{array}{l}\text { Institute of Numerical Mathematics of the } \\
\text { Russian Academy of Sciences }\end{array}$ & $120 \times 180$ & 1 \\
\hline IPSL-CM6A-LR & Institute Pierre-Simon Laplace (IPSL) & $143 \times 144$ & 3 \\
\hline KACE-1-0-G & $\begin{array}{l}\text { National Institute of Meteorological } \\
\text { Sciences/Korea Meteorological } \\
\text { Administration (NIMS-KMA) }\end{array}$ & $144 \times 192$ & 3 \\
\hline MCM-UA-1-0 & The University of Arizona (UA) & $80 \times 96$ & 1 \\
\hline MIROC6 & Atmosphere and Ocean Research & $128 \times 256$ & 3 \\
\hline MIROC-ES2L & $\begin{array}{l}\text { Institute (University of Tokyo), } \\
\text { National Institute for Environmental } \\
\text { Studies and Japan Agency for Marine- } \\
\text { Earth Science and } \\
\text { Technology (MIROC) }\end{array}$ & $64 \times 128$ & 1 \\
\hline MPI-ESM1-2-HR & $\begin{array}{l}\text { Max Planck Institute for Meteorology } \\
\text { (MPI-M) }\end{array}$ & $192 \times 384$ & 2 \\
\hline MRI-ESM2-0 & Meteorological Research Institute (MRI) & $160 \times 320$ & 1 \\
\hline NESM3 & $\begin{array}{l}\text { Nanjing University of Information } \\
\text { Science and Technology (NUIST) }\end{array}$ & $96 \times 192$ & 2 \\
\hline NorESM2-MM & $\begin{array}{l}\text { Bjerknes Centre for Climate } \\
\text { Research (BCCR) }\end{array}$ & $192 \times 288$ & 1 \\
\hline UKESM1-0-LL & $\begin{array}{l}\text { Natural Environment Research Council } \\
\text { and the Met Office Hadley Centre }\end{array}$ & $144 \times 192$ & 3 \\
\hline
\end{tabular}

historical runs covered the period from 1850 to 2014, and the period 1979-2014 was analyzed to determine the present-day climate in comparison with observations. The future change here means the change of climatological mean projected for the period 2065-2100 relative to that simulated for the period 1979-2014. The local summer means June-September (JJAS) for the NH and December-March (DJFM) for the SH; local winter means DJFM over for the $\mathrm{NH}$ and JJAS for the $\mathrm{SH}$.

\section{b. Definition of regional monsoon domain}

Regional monsoon domains have been defined differently by using diverse variables and criteria (e.g., Song et al. 2014; Menon et al. 2013; Geil et al. 2013; Jones and Carvalho 2013), making quantitative assessment and comparison of different regions difficult. Here the monsoon domain is objectively defined by uniform criteria proposed by Wang and Ding (2008). Figure 1 shows the domains for eight regional monsoons. The vast Asian monsoon was divided into three submonsoon systems, namely the SA, EA, and the western North Pacific (WNP), which are separated roughly by $105^{\circ} \mathrm{E}$ (the eastern edge of the Tibetan Plateau) and $22.5^{\circ} \mathrm{N}$ between the tropical WNP and subtropical EA monsoon (Wang et al. 2003). Note that the SA monsoon covers not only India but also the adjacent land and ocean south of the Tibetan Plateau. Changes in land monsoon often differ from the changes in oceanic monsoon (Fasullo 2012), and therefore our study mainly focuses on the land monsoon (the green shading shown in Fig. 1) except for the WNP monsoon. The North American monsoon domain 


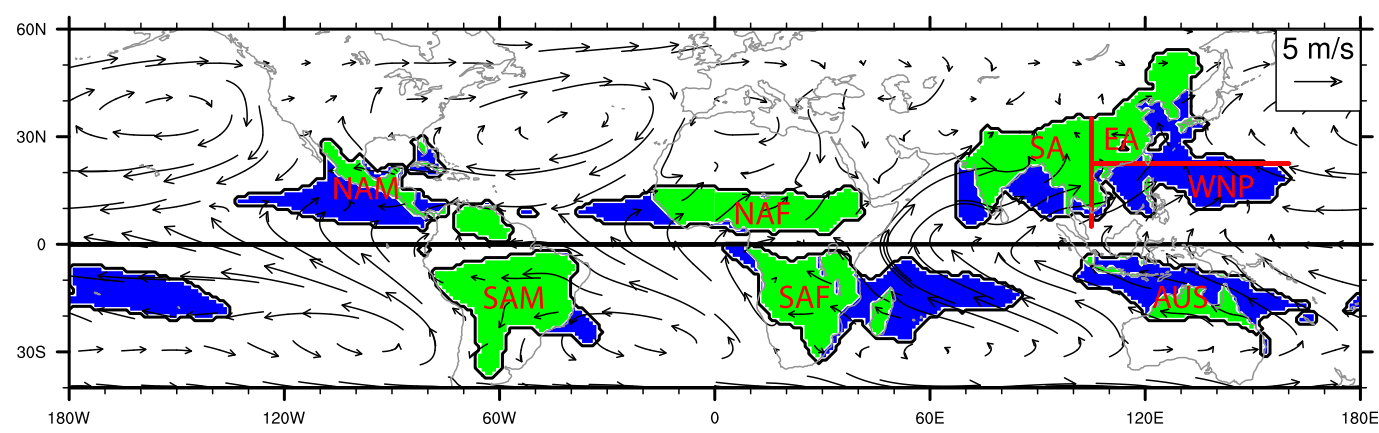

FIG. 1. The monsoon precipitation domains defined by (a) the summer-minus-winter precipitation exceeding $300 \mathrm{~mm}$ and (b) the summer precipitation exceeding $55 \%$ of the annual total precipitation, where summer means May-September (MJJAS) for the NH and November-March (NDJFM) for the SH (Wang and Ding 2008). The monsoon domains include eight regional monsoons: northern Africa (NAF), South Asia (SA), East Asia (EA), western North Pacific (WNP), North America (NAM), southern Africa (SAF), Australia (AUS), and South America (SAM). The SA, EA, and WNP monsoon regions are separated by $105^{\circ} \mathrm{E}$ and $22.5^{\circ} \mathrm{N}$ (red lines). Green and blue shadings indicate the land and ocean monsoon region, respectively. Vectors denote the August mean 925$\mathrm{hPa}$ winds $\left(\mathrm{m} \mathrm{s}^{-1}\right)$.

covers not only western Mexico and Arizona but also Central America and Venezuela. The SAF monsoon has not been well recognized in the literature. However, both the surface winds reversal (Ramage 1971) and the rainfall contrast (Wang 1994) between the solstice seasons indicate that the SAF is a strong monsoon region.

\section{c. Precipitation attribution analysis}

To attribute the future precipitation changes, we start from the vertically integrated moisture conservation equation in the tropospheric $p$ coordinates:

$$
\left\langle\frac{\partial q}{\partial t}\right\rangle+\langle\nabla \cdot(q \mathbf{V})\rangle=E-P
$$

where the angle brackets denote the column integration from 1000 to $100 \mathrm{hPa}, \nabla$ is the gradient operator, $q$ is the specific humidity, $\partial / \partial t$ is the local rate of change, $\mathbf{V}$ is the $3 \mathrm{D}$ wind vector, and $E$ and $P$ are the surface evaporation and precipitation, respectively. Here other small moisture source/sink terms are omitted.

For monthly or seasonal mean motion, the local rate of change can be neglected. Using continuity equation and the kinematic boundary conditions at the surface and $100 \mathrm{hPa}$ by assuming the vertical boundaries are material surfaces, one can show that the column integrated moisture convergence $\langle\nabla \cdot(q \mathbf{V})\rangle$ can be expressed as $\langle\nabla \cdot(q \mathbf{V})\rangle=\langle\omega(\partial q / \partial p)\rangle+$ $\left\langle\mathbf{V}_{h} \cdot \nabla q\right\rangle$; thus, Eq. (1) becomes

$$
P=E-\left\langle\omega \frac{\partial q}{\partial p}\right\rangle-\left\langle\mathbf{V}_{h} \cdot \nabla q\right\rangle,
$$

where $\langle\omega(\partial q / \partial p)\rangle$ and $\left\langle\mathbf{V}_{h} \cdot \nabla q\right\rangle$ denote the column integrated vertical and horizontal moisture advection, respectively.

Taking a two-layer approximation of the troposphere with the interface at $500 \mathrm{hPa}$, and assuming the mean specific humidity in the lower troposphere equals the specific humidity at $850 \mathrm{hPa}\left(q_{850}\right)$ and that upper tropospheric specific humidity is negligibly small, we have the following approximations:

$$
\begin{aligned}
\left\langle\omega \frac{\partial q}{\partial p}\right\rangle & \approx \frac{1}{g}\left(\omega_{500} q_{850}\right), \\
\left\langle\mathbf{V}_{h} \cdot \nabla q\right\rangle & \approx \frac{1}{g}\left(\mathbf{V}_{850} \cdot \nabla q_{850}\right) .
\end{aligned}
$$

Equation (2) can then be simplified as

$$
P \approx E-\frac{1}{g}\left(\omega_{500} q_{850}\right)-\frac{1}{g}\left(\mathbf{V}_{850} \cdot \nabla q_{850}\right) .
$$

For analysis of the regional mean LMP, Eqs. (2) and (5) should be taken an area average over the entire LMP domain.

In the moisture budget analysis, we will estimate contributions from the three right-hand terms of Eq. (2) at each regional monsoon. As shown in section 5 , the regional mean horizontal moisture advection is often negligibly small, and regional mean surface evaporation in most regional monsoons is a relatively small compared to the regional mean vertical moisture advection by upward motion at $500 \mathrm{hPa}$. In this case, Eq. (5) could be further approximated by

$$
P \approx-\frac{1}{g}\left(\omega_{500} q_{850}\right)
$$

In section 5, the accuracy of this approximation is tested for each monsoon region.

\section{CMIP 6 models' performance and common biases}

Four variables have been considered important for evaluation. The first two evaluate precipitation climatology, including the summer mean precipitation and the monsoon intensity defined by the ratio of local summer-minus-winter precipitation to the annual total precipitation. The last two evaluate the year-to-year variability of precipitation, including the standard deviation of summer mean precipitation and the first empirical orthogonal function (EOF1) mode of the monsoon-year precipitation. We use the pattern correlation coefficient (PCC) to measure the "similarity" between two spatial patterns and the 

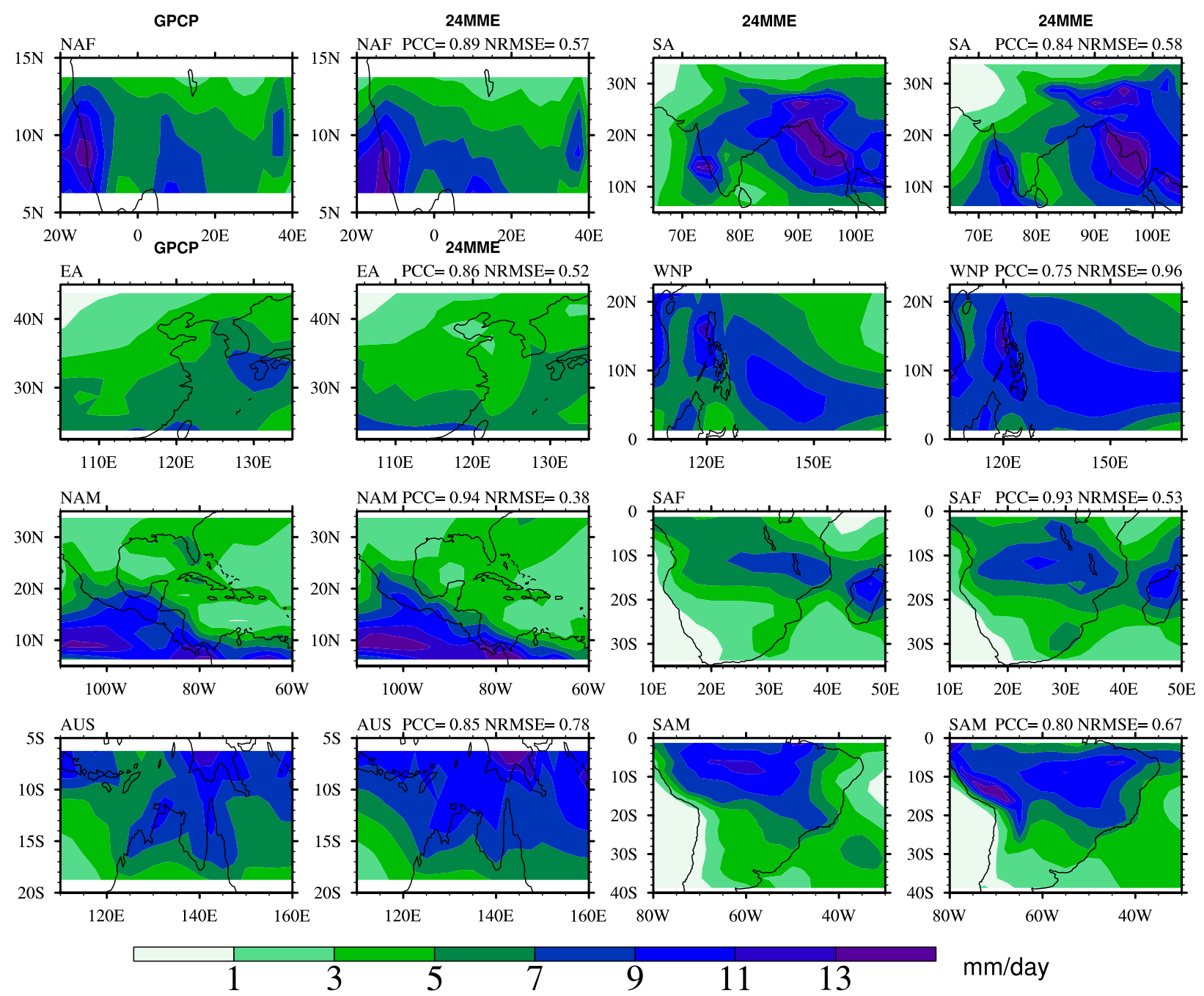

FIG. 2. Comparison of observed and model-simulated local summer (JJAS in the NH and DJFM in the SH) mean precipitation climatology (1979-2014; $\mathrm{mm} \mathrm{day}^{-1}$ ) over each regional monsoon derived from the GPCP and 24 models' MME simulation. The PCC and NRMSE are given at the top-right corners of the simulation panels.

normalized root-mean-square error (NRMSE), which is the RMSE normalized by the observed mean standard deviation, to measure the mean biases and averaged spatial distribution errors. It should be mentioned that the overall performances of the precipitation climatology shown in Figs. 2 and 3 are based on multiple ensemble members, while a single run multimodel ensemble (MME) is used for the overall assessment of the year-to-year variability of precipitation shown in Figs. 4 and 5.

\section{a. Precipitation climatology}

As shown in Fig. 2, a multimodel ensemble with 24 members (24MME) reproduces well the observed local summer mean precipitation with the highest skill over the NAM $(\mathrm{PCC}=0.94$ and NRMSE $=0.38)$ and the lowest skill over the WNP (PCC = 0.75 , NRMSE $=0.96$ ). The common bias is the overproduced summer rainfall in the WNP and three SH monsoon regions where the bias normalized by the corresponding observed means ranges from $1.2 \%$ (SAM) to $22 \%$ (WNP and SAF). Localized dry biases are seen in India and northern EA. Over EA, the observed rainfall shows southwest-northeast tilted contours, which reflect the subtropical frontal zone rainfall, whereas the $24 \mathrm{MME}$ simulates an erroneous zonal structure.

The monsoon intensity (MI) represents the degree of the contrast between wet summer and dry winter (annual range) in comparison with its annual mean precipitation. $\mathrm{MI}>0.25$ means the annual range exceeds $25 \%$ of the annual mean. Here we consider MI $>0.25$ as a threshold for a "monsoon flavor"; $\mathrm{MI}>0.5$ indicate a strong monsoon in terms of seasonal distribution of rainfall. In contrast, $\mathrm{MI}<-0.25$ is considered as a Mediterranean regime where local winter has significantly more rainfall than summer.

The 24MME simulates monsoon intensity very well (Fig. 3). The PCCs in all regional monsoons range from 0.87 to 0.95 and NRMSEs from 0.33 to 0.58 . The monsoon intensity in four 

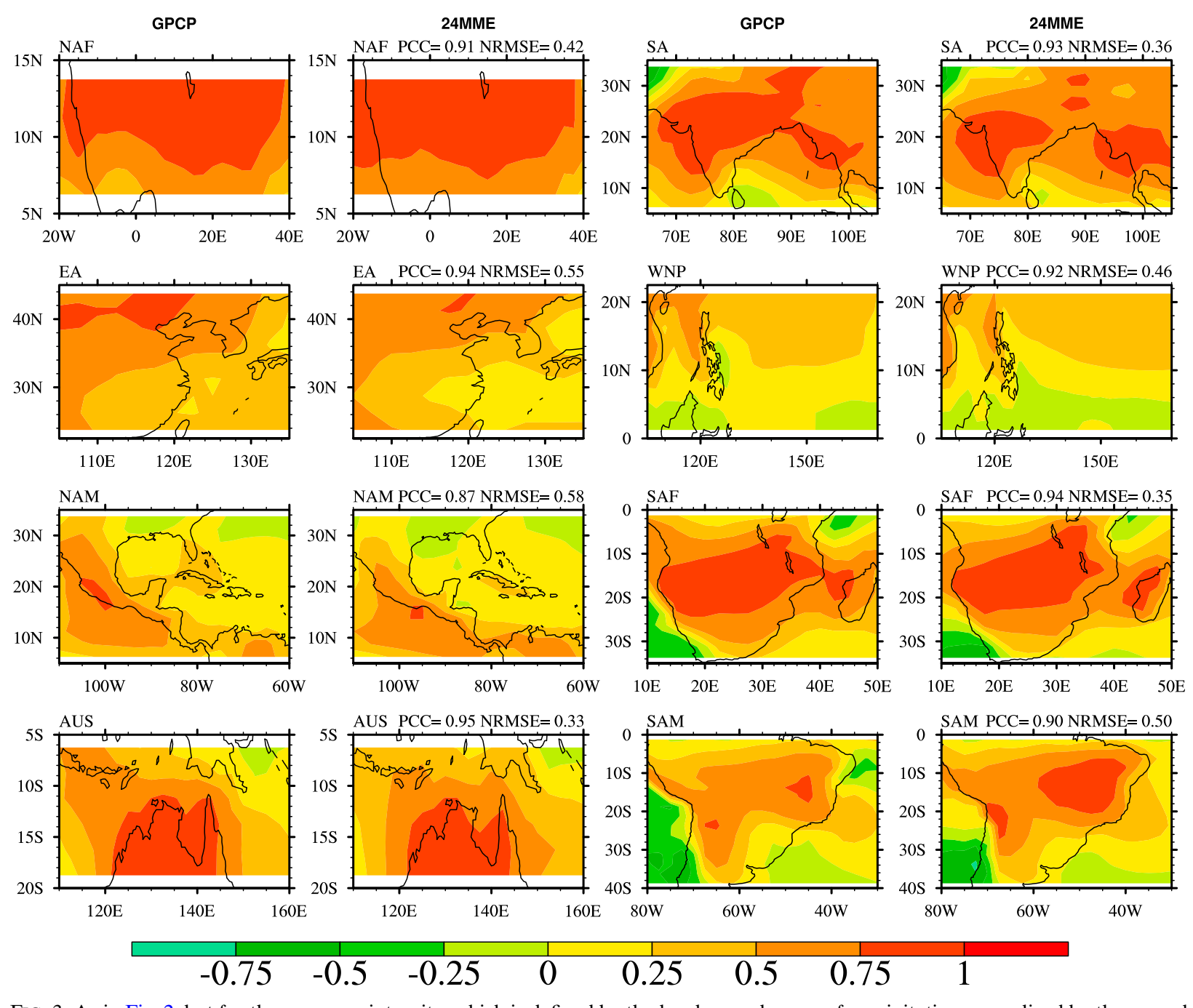

FIG. 3. As in Fig. 2, but for the monsoon intensity, which is defined by the local annual range of precipitation normalized by the annual mean precipitation. The annual range is defined by MJJAS minus NDJFM in the NH and NDJFM minus MJJAS in the SH.

strong monsoon regions (SA, NAF, AUS, and SAF) is simulated better than in four weak monsoon regions (EA, NAM, SAM, and WNP) as indicated by the NRMSE.

\section{b. Precipitation variability}

Figure 4 shows the simulated standard deviation (SD) averaged over the 24 models. A notable common bias is that the simulated amplitude of the SD is higher than that derived from the observation in all regional monsoons. The percentage bias ranges from $11.5 \%$ (NAM) to $41.4 \%$ (SAF), and large biases are also seen in SA (32.5\%) and SAM (28.5\%). The PCCs normally range from 0.74 to 0.89 , except for AUS (0.49). The largest errors (NRMSE $>1$ ) are over SA, WNP, AUS, and $\mathrm{SAF}$, where the variances over the ocean and adjacent regions are considerably overestimated.

Figure 5 evaluates the simulated leading patterns of the interannual variations of the monsoon-year precipitation and their relationships with ENSO. The monsoon-year defined from May to the next April (Yasunari 1991) not only reflects the natural monsoon seasonal cycle in both hemispheres but also coincides with a typical life cycle of an El Niño event from onset to decay (Wang et al. 2012). The observed EOF1 modes over most monsoon regions are significantly separated from other EOF modes by the statistical significance test (North et al. 1982) except in the NAF. The EOF1 modes are simulated reasonably realistically over most regions except over the NAF and WNP regions. The amplitudes of EOF1 over the NAF are substantially underestimated.

El Niño-Southern Oscillation (ENSO) drives global tropical monsoon rainfall variability, but most regional summer monsoons have nonstationary relationships with ENSO (Webster et al. 1999). Table 2 shows the relationships between ENSO and the leading modes of regional monsoon variability. In observation, the oceanic Niño index (ONI) is significant, at a confidence level of $95 \%$, correlated with the first principal component (PC1) of each RM pattern except the EA. The 

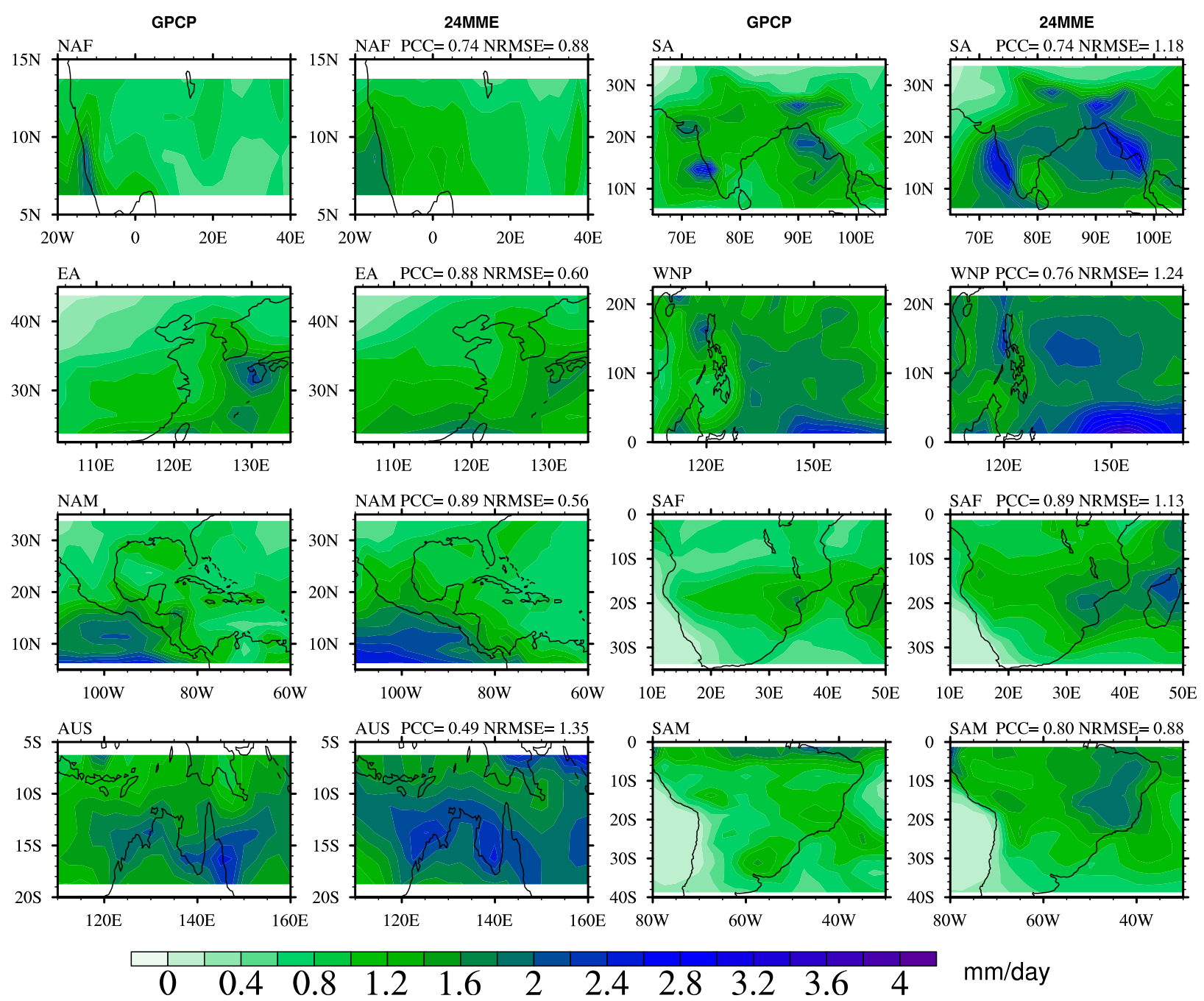

FIG. 4. As in Fig. 2, but for the standard deviation of local summer mean precipitation ( $\left.\mathrm{mm} \mathrm{day}^{-1}\right)$. The SD of $24 \mathrm{MME}$ is the average of the standard deviation obtained from the 24 individual models.

spatial patterns of the EOF1 of year-to-year variation are generally realistic except for the NAF (Fig. 5). The relationships between ENSO and regional monsoon EOF1 are captured reasonably well for most regional monsoons except for the SA and perhaps NAF monsoons (Table 2). The simulated RM-ENSO relationship is based on single runs of the best 10 models (B10MME; the next section will discuss how to select the best models in detail) by considering that more models can better eliminate individual models' biases and better estimate the uncertainty.

\section{c. Overall evaluation}

Figure 6 compares the PCC skills of the simulated climatology and variability for individual models and 24MME. The rainfall climatology is simulated significantly better than variability. The monsoon intensity is best simulated with PCCs ranging primarily from $\sim 0.6$ to $\sim 0.95$, and the summer mean precipitation also simulated well with most PCCs ranging from
0.5 to 0.9 except for the WNP (Fig. 6a). However, the simulated PCCs for both the leading EOF pattern and the year-to-year variance show the largest spreads from 0 to 0.9 (Fig. 6b).

Figure 7 summarizes PCC skills of the simulated climatology and variability shown in Fig. 6. To quantitatively assess the overall performance of each model in each region, we defined a combined PCC skill score, which is the arithmetic mean of the four metrics of PCC scores with equal weights. Figure 7a shows the skill dependence on regions. The SA, EA, NAM, SAF, and SAM monsoons are well simulated with the 24MME averaged PPC scores ranging from 0.83 to 0.89 , while the AUS, NAF, and WNP monsoons are simulated relatively poorly with the 24MME averaged PPC scores about 0.75. The low skills in simulated AUS, NAF, and WNP are mainly due to the large errors in the interannual variance and the leading EOF modes (Figs. 4 and 5).

Figure $7 \mathrm{~b}$ compares the combined simulation PCC skills among different models. The eight-region averaged PCC skills 

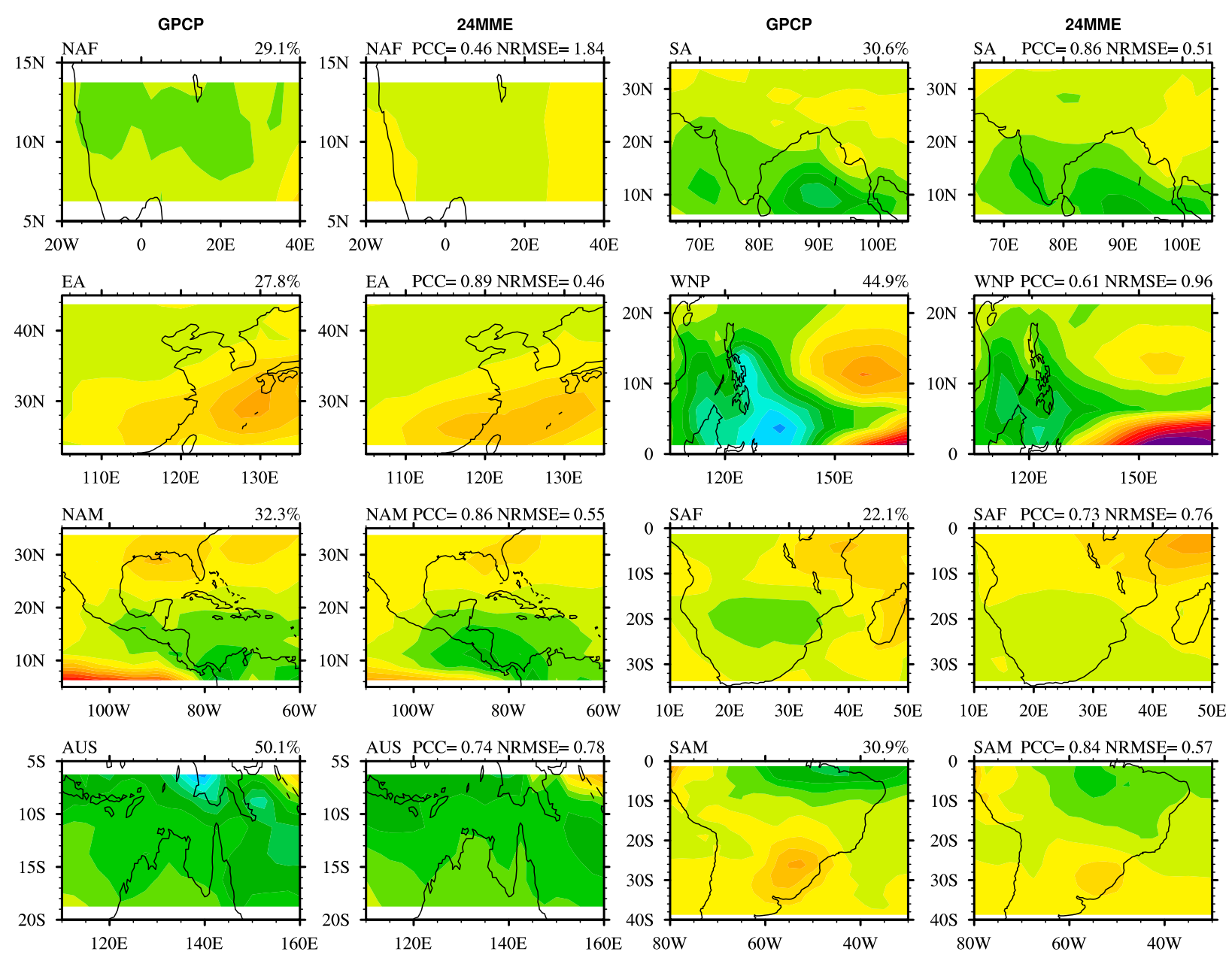

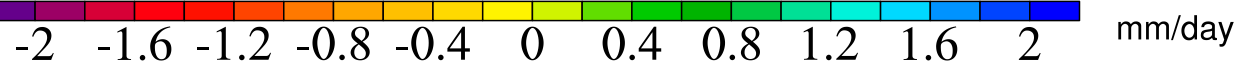

FIG. 5. As in Fig. 2, but for the EOF1 of the monsoon-year precipitation ( $\mathrm{mm} \mathrm{day}^{-1}$ ). The 24 models' ensemble mean result is the average of the EOF1 modes obtained from the 24 individual models. The monsoon-year is defined from May to the next April.

vary considerably by model, ranging from $\sim 0.55$ to $\sim 0.77$ with the $24 \mathrm{MME}$ skill $=0.83$. Note that the $24 \mathrm{MME}$ not only has the highest averaged score, but also shows the smallest differences among different regional monsoons (from 0.75 to 0.89 ).

There are 10 models having an averaged combined PCC score higher than 0.7 (B10MME, including CESM2, CESM2WACCM, EC-Earth3-Veg, FIO-ESM-2-0, GFDL-CM4, GFDLESM4, HadGEM3-GC31-LL, MIROC6, NorESM2-MM, and UKESM1-0-LL). Meanwhile, we also select the best five models (B5MME, including CESM2, CESM2-WACCM, MIROC6, NorESM2-MM, and UKESM1-0-LL). Results shown in Fig. 7 suggest that the $24 \mathrm{MME}, \mathrm{B} 5 \mathrm{MME}$, and B10MME have almost the same simulation skills. The 24MME is slightly better than B5MME and B10MME, but the small differences between them are unlikely statistically significant. We will, therefore, examine the ensemble simulation and projection provided by multiple ensemble members of the 24 models (24MME) except for the determination of the year-to-year variability of precipitation, which has to use a single run because the multiple-member ensemble mean would artificially reduce the internal variability. In addition, results shown later (see Figs. 11-15) are based on the single-run $24 \mathrm{MME}$ as there are few discrepancies between the multiple members of $24 \mathrm{MME}$ and the single-run 24MME (Fig. 7).

\section{Projected future changes of regional monsoon}

\section{a. The mean and variability of the regional land monsoon precipitation}

Despite the fact that the changes are not uniform within a regional monsoon domain, it is always worthwhile to first examine the integrated properties of the regional monsoons. To this end, we computed the LMP change averaged over each regional land monsoon domain during local summer, local winter, and the whole year (Fig. 8). In Fig. 8, the confidence level of the 24MME results follows the likelihood presented in 
TABLE 2. Simultaneous correlation coefficient (CC) during a monsoon year (May-April) between the PC1 and the ONI in the observation, historical run, and SSP2-4.5 run derived from the 10 best CMIP6 models (CESM2, CESM2-WACCM, EC-Earth3-Veg, FIO-ESM-2-0, GFDL-CM4, GFDL-ESM4, HadGEM3-GC31LL, MIROC6, NorESM2-MM, UKESM1-0-LL). The ONI is the SST anomalies averaged over the Niño 3.4 region $\left(5^{\circ} \mathrm{S}-5^{\circ} \mathrm{N}, 120^{\circ}-\right.$ $\left.170^{\circ} \mathrm{W}\right)$. Two asterisks (**) represent significance at the $95 \%$ confidence level.

\begin{tabular}{llll}
\hline \hline CC & Observation & Historical & SSP2-4.5 \\
\hline NAF & $-0.34 * *$ & -0.12 & -0.17 \\
SA & $-0.66 * *$ & -0.16 & $-0.60 * *$ \\
EA & -0.26 & -0.23 & -0.24 \\
WNP & $-0.90 * *$ & $-0.79 * *$ & $-0.81 * *$ \\
NAM & $-0.87 * *$ & $-0.78 * *$ & $-0.75 * *$ \\
SAF & $-0.57 * *$ & $-0.40 * *$ & $-0.62 * *$ \\
AUS & $-0.84 * *$ & $-0.78 * *$ & $-0.74 * *$ \\
SAM & $-0.73 * *$ & $-0.66 * *$ & $-0.77 * *$ \\
\hline
\end{tabular}

the IPCC Fifth Assessment Report (Mastrandrea et al. 2010). The box contains $66 \%$ of the data, which represents the range of likely occurrence $(66 \%-100 \%)$. The vertical dashed line represents the range from $5 \%$ to $95 \%$, which denotes a "very likely" range (90\%-100\%). Over the $\mathrm{NH}$, the projected summer mean LMP over SA very likely increases, and over EA, NAF, and WNP likely increases, but the NAM LMP likely decreases (Fig. 8a). The highest precipitation sensitivities are seen in $\operatorname{EA}\left(4.6 \%{ }^{\circ} \mathrm{C}^{-1}\right)$ and $\mathrm{SA}\left(4.1 \%{ }^{\circ} \mathrm{C}^{-1}\right)$. These sensitivities are lower than those projected by CMIP5 models (Lee and Wang 2014). Interestingly, in the NH regional monsoons, the annual mean change is basically determined by the local summer precipitation changes, and the summer and winter precipitation changes are in the same direction; however, in the $\mathrm{SH}$ the summer and winter changes are in opposite directions, resulting in insignificant changes in the annual mean precipitation (Fig. 8c). Notably, the EA winter monsoon LMP is the only one that will very likely increase. Of interest is that during winter, the projected LMP changes over all SH regions (i.e., SAF, AUS, and SAM) will likely decrease. As shown by Wang et al. (2020b), the weakening of the winter SH monsoon is closely linked to the enhanced $\mathrm{NH}$ summer monsoon, which drives descent over the SH monsoon regions through Hadley circulation. It should be noted that the uncertainties of the local winter precipitation changes are more substantial than those of the local summer rainfall changes over each RM (note the different scales between Figs. $8 \mathrm{a}$ and $8 \mathrm{~b}$ ). The projected uncertainties measured by intermodel spreads are the largest over the AUS and NAF. In addition, the summer NAM and winter SAM also show large spreads.

Figure 9 shows the changes in the rainfall standard deviation. Comparison of Figs. 8 and 9 indicates that the changes of $\mathrm{SD}$ seem to be in the same direction as the changes in the corresponding mean LMP except in the NAM, but the SD changes are less significant due to large intermodel spreads. The projected SD likely increases over SAF and SAM during local summer, and over WNP during winter. The annual mean precipitation variability likely increases only over SA and SAM, although most regions show an increase.

\section{b. The leading mode of interannual variability and RM-ENSO relationship}

It has been projected that, under anthropogenic forcing, global monsoon rainfall variability is projected to intensify, and the relationships between monsoon and El Niño strengthen (Hsu et al. 2013). The spatial structures of the leading mode of interannual variation of Asian-Australian monsoon precipitation will not change appreciably (Wang et al. 2014), but the ENSO-AAM relationship will become stronger (Jourdain et al. 2013). However, the connection between the Indian monsoon rainfall and Niño-3 SST is projected to decrease, particularly after 2050 (Ashrit et al. 2005). More frequent occurrences of extreme ENSO events (Wang et al. 2019) could enhance the extreme monsoon rainfall in the future (Cai et al. 2014).

The spatial patterns of the leading modes of the monsoonyear precipitation during 2065-2100 derived from the SSP2-4.5 are very similar to those during 1979-2014 in the historical run with PCCs normally exceeding 0.90 except over NAF (PCC $=$ 0.73 ) (Fig. 10). The projected variances are also similar, except for a moderate increase in SAM. In a recent analysis of the CMIP6 results, the projected correlation between the principal component of global monsoon precipitation and simultaneous Niño 3.4 SST anomaly during a monsoon-year is enhanced in the SSP2-4.5 $(r=-0.83)$ compared to the HIST run $(r=-0.65)$ (Wang et al. 2020b), which is consistent with the CMIP5 assessment (Hsu et al. 2013). On the regional scale, however, the projected ENSO-monsoon relationship based on the B10MME will only be enhanced over SA and perhaps SAF, but remains unchanged in other regions (Table 2).

\section{c. Changes in integrated measures of regional monsoon circulations}

Regional precipitation changes closely depend on the atmospheric circulation change. First, we need to define circulation indices for each regional monsoon. Yim et al. (2014) suggested that the enhanced regional monsoon precipitation is commonly characterized by a low-level cyclonic circulation; therefore, the circulation intensity indices over most monsoon regions are defined by the meridional shear vorticity of the $850-\mathrm{hPa}$ zonal winds (U850). However, indices proposed by Yim et al. (2014) reflect the total precipitation averaged over each region, including both land and ocean. Here we concern with the LMP only, so we reexamined the simultaneous correlation coefficient map of the observed monthly mean U850 with the averaged LMP during local summer over each region (figure not shown) and redefined the regional monsoon circulation indices that reflect the corresponding LMP variability. Table 3 lists definitions of the circulation indices for each RM. The circulation indices are defined by the meridional shear of 850 $\mathrm{hPa}$ zonal winds except over EA, NAF, and SAF. The NAF monsoon circulation index is defined by the westerly monsoon strength: $\mathrm{U} 850$ averaged over $0^{\circ}-15^{\circ} \mathrm{N}, 30^{\circ}-30^{\circ} \mathrm{W}$. The 
(a) Climatology (b) Variability
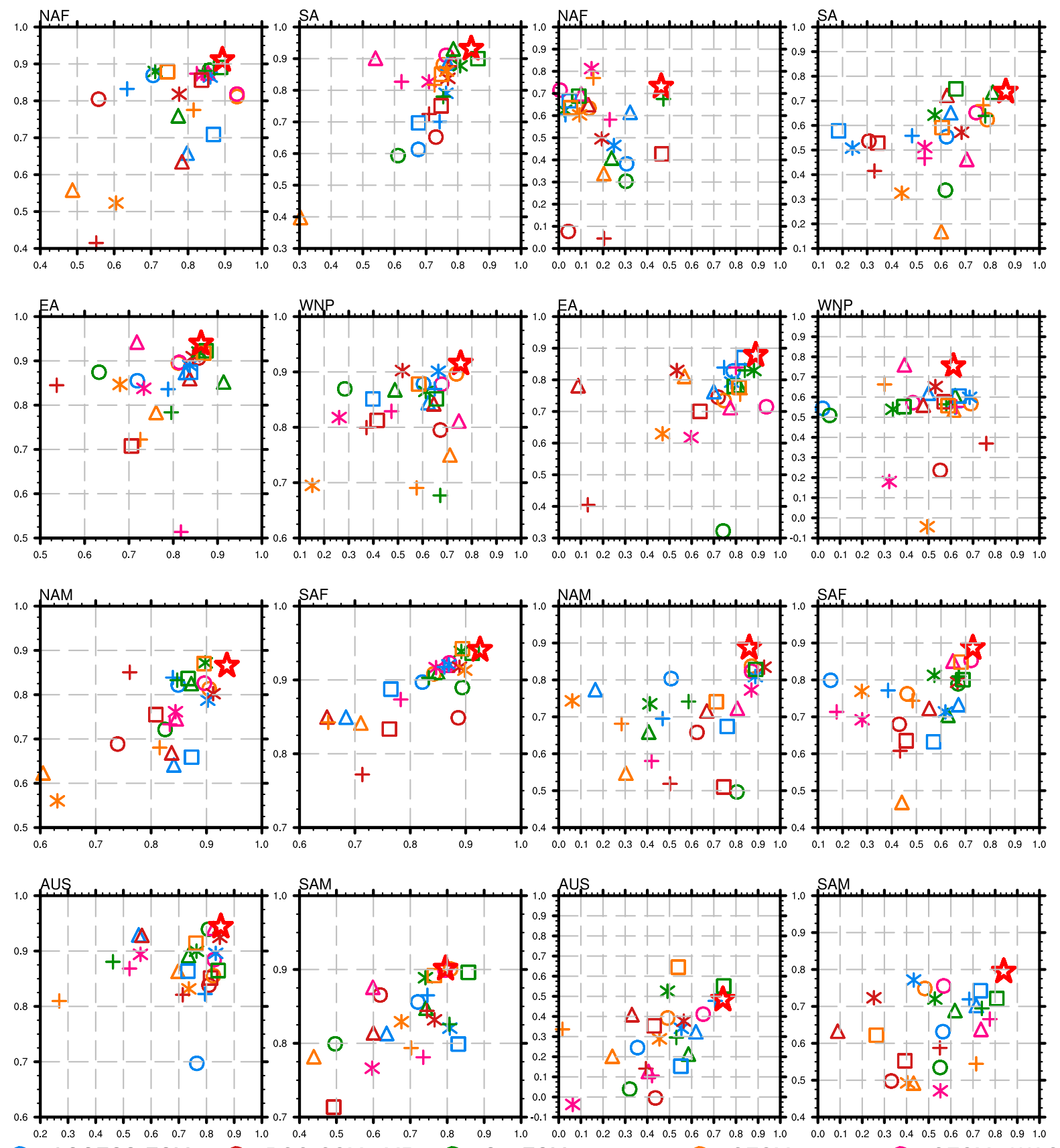

O ACCESS-ESM1-5O BCC-CSM2-MR

O CanESM5

- CESM2

O CESM2-WACCM
$\triangle$ CNRM-CM6-1
$\triangle$ CNRM-ESM2-1
$\Delta$ EC-Earth3-Veg
$\triangle$ FGOALS-g3
$\triangle$ FIO-ESM-2-0
* GFDL-CM4
* GFDL-ESM4
* HadGEM3-GC31-LL * INM-CM5-0
* IPSL-CM6A-LR
+ KACE-1-0-G
+ MCM-UA-1-0
+ MIROC6
MRI-ESM2-0
NESM3
+ MIROC-ES2L
+ MPI-ESM1-2-HR

FIG. 6. Assessment of the simulation skills in the regional monsoon precipitation for 24 individual CGCMs, and the 24MME. The evaluations are based on the pattern correlation coefficient between the observation (GPCP) and CMIP6 historical experiment over 1979-2014. (a) Climatology: areaaveraged summer mean precipitation (abscissa) and regional monsoon intensity (ordinate). (b) Variability: the spatial structure of the first EOF mode of the monsoon-year precipitation (abscissa) and the standard deviation of the summer mean precipitation (ordinate). 
(a)

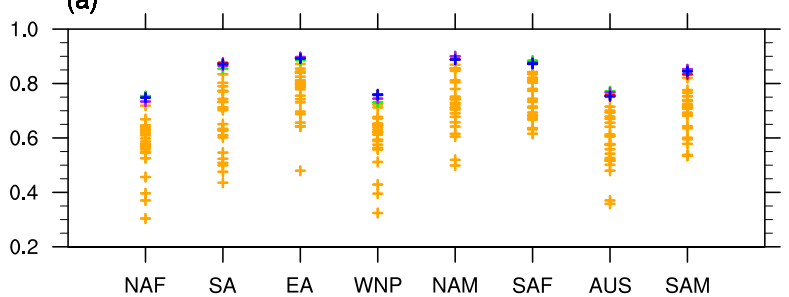

(b)

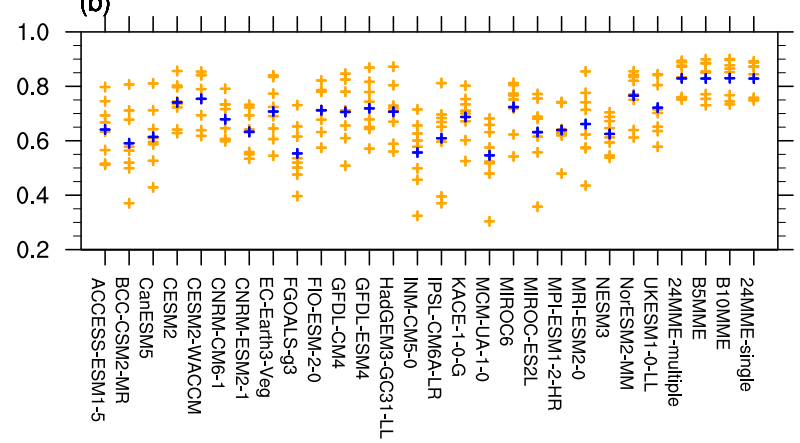

FIG. 7. Overall assessment of the simulation skills for (a) each regional monsoon and (b) each model and their MMEs. The simulation score is obtained by the arithmetic mean of the PCC scores for the four evaluation variables with equal weight. In (a) the orange crosses represent 24 individual models in multimember runs, and the red, green, purple, and blue crosses denote multimember runs' 24MME, B5MME, B10MME, and the single-member run 24MME, respectively. In (b) for the multimember runs' 24MME, B5MME, B10MME, and the single-member run 24MME, the orange crosses represent each region and the blue crosses represent the average score for the eight regions.

EA summer monsoon circulation index is defined by the 850 -hPa meridional winds (V850) averaged over $20^{\circ}-45^{\circ} \mathrm{N}$, $110^{\circ}-130^{\circ} \mathrm{E}$, as the subtropical EA monsoon is characterized by an annual reversal of the meridional winds (Guo 1983) in response to the thermal contrast between the Asian continent and western North Pacific. Given the high elevation of South Africa, the SAF monsoon circulation index is defined by the meridional shear of zonal winds at $700 \mathrm{hPa}$.

The transient responses of the land monsoon circulation indices from 1979 to 2100 over each monsoon region are shown in Fig. 11. The monsoon circulation indices exhibit slightly increasing trends over SA and EA and slightly decreasing trend over the WNP and SAM, but they are not statistically significant as the intermodel spread measured by the one standard deviation is inclusive of zero. However, the projected NAM, AUS, and SAF circulation indices show significant decreases, and the NAF circulation index shows a significant increase. Overall, the lowlevel regional monsoon circulations would either decrease or show no significant changes. It should be mentioned that in CMIP5, the SA monsoon circulation shows a decreasing trend, yet it is insignificant (Pachauri et al. 2014; Wang et al. 2014). (a) Local summer units: $\% /{ }^{\circ} \mathrm{C}$

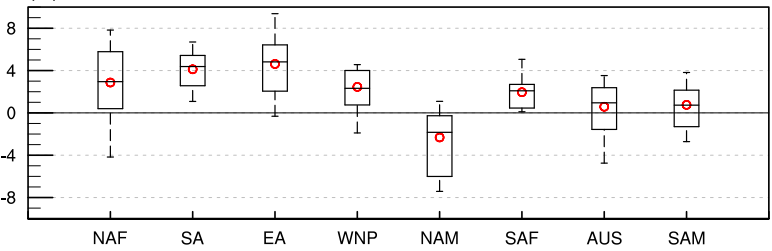

(b) Local winter

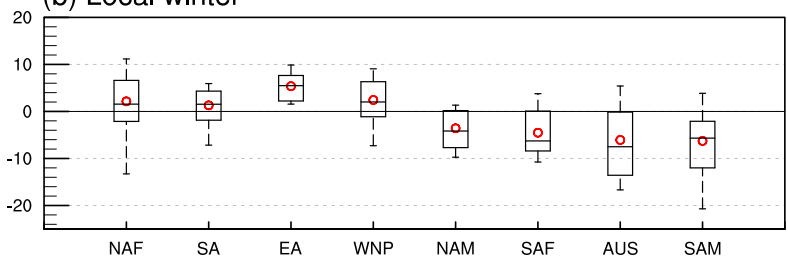

(c) Annual mean

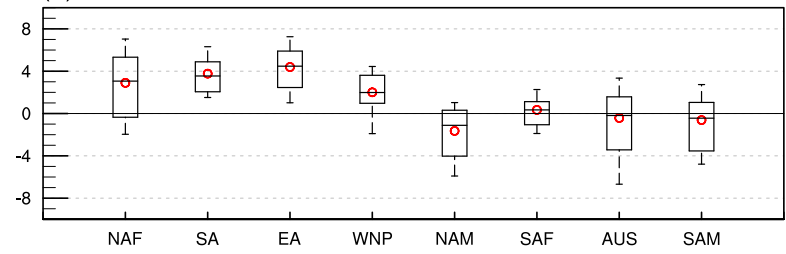

FIG. 8. Projected regional land monsoon precipitation sensitivity under the SSP2-4.5, i.e., the percentage change (20652100 relative to $1979-2014)$ per $1{ }^{\circ} \mathrm{C}$ global warming $\left(\%{ }^{\circ} \mathrm{C}^{-1}\right)$ derived from 24 CMIP6 models for (a) local summer, (b) local winter, and (c) annual mean land monsoon precipitation at each regional monsoon. Local summer means JJAS in $\mathrm{NH}$ and DJFM for SH, and local winter is the opposite. The upper (lower) edge of the box represents the 83 rd (17th) percentile, so the box contains $66 \%$ of the model projection data and represents the "likely" range. The horizontal line within the box is the median. The red circle is the mean. The vertical dashed line segments represent the "very likely" range from $5 \%$ to $95 \%$.

\section{d. Changes in spatial patterns of precipitation and circulation}

Until now, the monsoon rainfall and circulation changes are examined in terms of the area-weighted mean. Figure 12 shows the patterns of the simulated present-day mean (1979-2014) and the changes (2065-2100 relative to 19792014) in the local summer precipitation and $850-\mathrm{hPa}$ winds over each monsoon region except the $700-\mathrm{hPa}$ winds over the SAF. The projected summer rainfall over the Asian monsoon region (EA, SA, WNP) is characterized by a nearly uniform increase in the future, which is consistent with the enhanced Asian low and relatively high pressure over the adjacent oceans. The monsoon circulation strengthens over northern India, but it weakens over southern India, indicating a northward shift of monsoon circulation, in agreement with the result of Menon et al. (2013). Due to the enhanced Saharan low and the westerlies to its south, a clear consensus on the future wetting central-eastern northern Africa is observed, but the western Sahel will see no change. The latter seems to disagree with the apparent dry westernmost Sahel projected in CMIP5 (Roehrig et al. 2013). The 
(a) Local summer

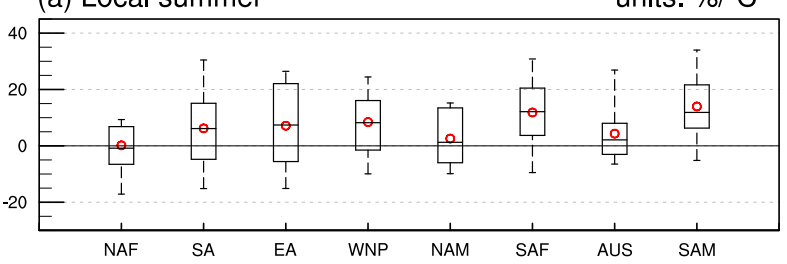

(b) Local winter

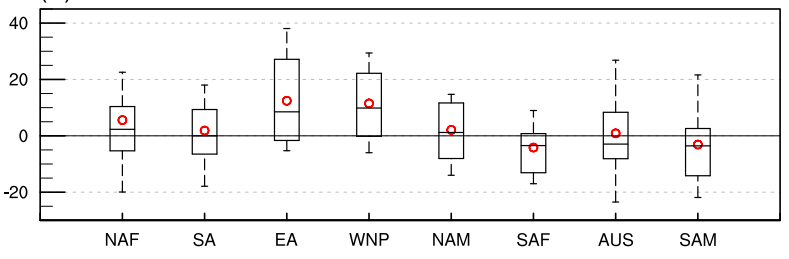

(c) Annual mean

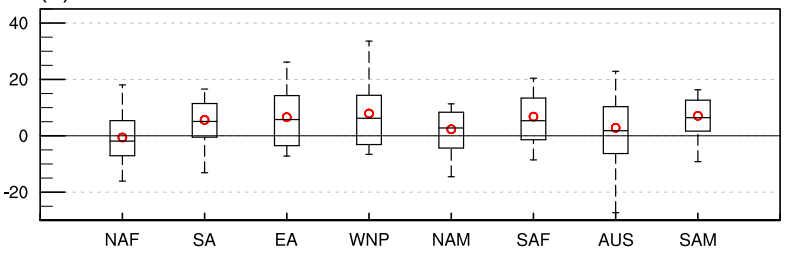

FIG. 9. As in Fig. 8, but for the projected standard deviation of the land monsoon precipitation sensitivity $\left(\%{ }^{\circ} \mathrm{C}^{-1}\right)$.

projected precipitation decreases over NAM are consistent with the anticyclonic anomalies over southern America and Mexico, which transport water vapor to the equatorial eastern Pacific but dry Central America. The result is in good agreement with the reduced NAM rainfall (Fig. 8a) and the associated circulation index (Fig. 11d). The AUS monsoon region will be controlled by an anomalous anticyclonic circulation, so the circulation index has a declining trend (Fig. 11e). The enhanced rainfall over the AUS monsoon region is mainly concentrated over the southern Indonesian archipelago to the north of the anticyclone. This result is different from the CMIP5 projection, which showed an increase of northern Australian precipitation while Indonesian precipitation change is uncertain (Jourdain et al. 2013). The circulation pattern changes over the southern Atlantic tend to enhance the precipitation over southeastern South America, but the anticyclonic anomaly over Amazon tends to reduce the local rainfall, which is in agreement with previous results (Seth et al. 2010). For the SAF monsoon region, more rainfall exhibits over the northern part of the SAF region, which corresponds to a local cyclonic trough. The meridional dipolar distribution of LMP changes in the three $\mathrm{SH}$ regional monsoons are generally consistent with the circulation changes.

\section{Attribution of future change and sources of projected uncertainty}

\section{a. Critical roles of the circulation changes in changing regional monsoon precipitation}

The processes that influence the future change of regional monsoon rainfall under anthropogenic forcing are complex. However, the principle of moisture conservation provides a simple framework to decipher complex processes. Moisture conservation requires, on a time scale of monthly or longer, precipitation being approximately balanced by the horizontal and vertical moisture advection plus surface evaporation [Eq. (5) in section 2].

Figure 13 shows the estimated contributions of the vertical and horizontal moisture advection and surface evaporation to the area-averaged summer LMP change (the 2065-2100 mean minus the 1979-2014 mean) for each monsoon region. In general, the area-averaged horizontal moisture advection $\left(\left\langle\mathbf{V}_{h} \cdot \nabla q\right\rangle\right)$ plays a negligible role (less than $\left.0.1 \mathrm{~mm} \mathrm{day}^{-1}\right)$ in all monsoon regions except in NAM $\left(-0.2 \mathrm{~mm} \mathrm{day}^{-1}\right)$ and EA $\left(0.2 \mathrm{~mm} \mathrm{day}^{-1}\right)$ where the moisture flux is dominated by northerly and southerly flow, respectively (Fig. 12). Meanwhile, the enhanced evaporation contributes to a moderate increase (by about $0.05-0.15 \mathrm{~mm} \mathrm{day}^{-1}$ ) in all regional monsoons except EA $\left(0.25 \mathrm{~mm} \mathrm{day}^{-1}\right)$, where surface evaporation has a considerable contribution. The enhanced surface evaporation is mainly caused by the surface temperature rise (one of the thermodynamic effects), which can reduce the near-surface air relative humidity (Fasullo 2012). Relative humidity over land reduces more than over the ocean as the land warms more than the ocean (Meehl et al. 2007). Note that the changes of the vertical moisture advection $[\langle\omega(\partial q / \partial p)\rangle]$ play a dominant role in all regional monsoons except AUS and SAM, where the summer LMP has no significant change (Fig. 8a). The diagnosed regional summer land monsoon precipitation changes are in good agreement with the counterparts projected by the $24 \mathrm{MME}$, although the diagnosis slightly overestimates the projected rainfall amount.

Given the minor contributions of the evaporation and horizontal moisture advection in most monsoon regions, the moisture conservation equation can be further simplified to Eq. (6) in section 2 after a two-layer approximation of the troposphere is made. Equation (6) indicates that a regionally averaged monthly or seasonal mean precipitation may be approximated by the product of upward motion $\left(-\omega_{500}\right)$ and the specific humidity at $850 \mathrm{hPa}\left(q_{850}\right)$ with proper scaling.

Figure 14 serves to test the above approximation. Indeed, the estimated precipitation by $-\omega_{500} q_{850}$ is highly correlated with the precipitation simulated by the $24 \mathrm{MME}$ for each regional monsoon as indicated by the correlation coefficients ranging from 0.90 to 0.97 and small RMSEs during 2015-2100, suggesting that Eq. (6) is a reasonable approximation. The systematic underestimation in EA with the highest RMSE is due to the neglect of the significant contributions from surface evaporation and horizontal advection (Fig. 13). Note also that the changes in the regional mean ascents shown in Fig. 14 are generally in good agreement with the corresponding changes of the regional monsoon circulation indices except the NAF (Fig. 11). This agreement suggests that the low-level circulation indices, which mainly reflect the low-level shear vorticity of zonal winds (Table 3), also reflect the midtropospheric vertical motion except for the NAF where the circulation index is defined by westerly itself.

There is no doubt that the increasing humidity contributes to increasing monsoon precipitation; however, the humidity 

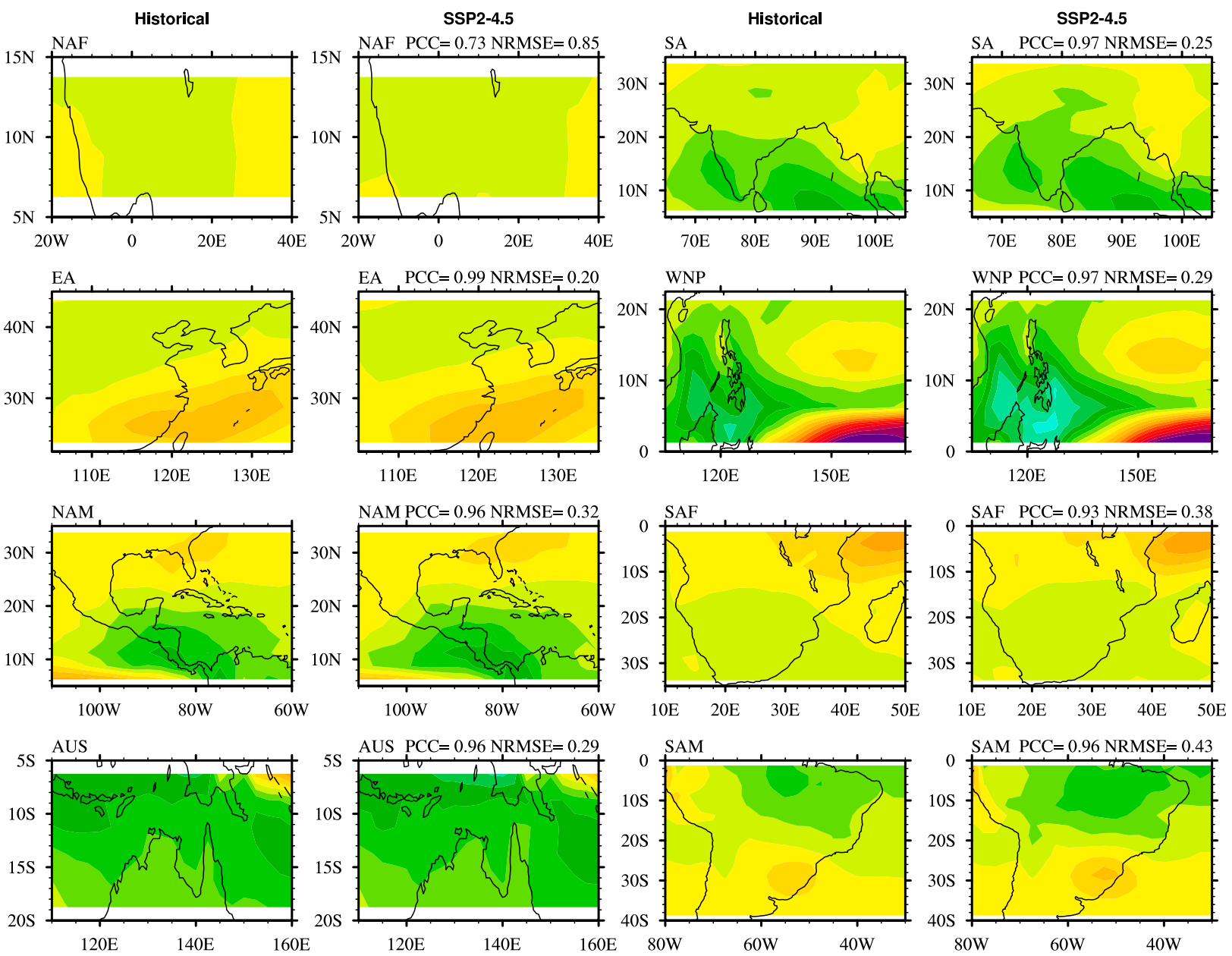

\section{$\begin{array}{llllllllllll}-2 & -1.6 & -1.2 & -0.8 & -0.4 & 0 & 0.4 & 0.8 & 1.2 & 1.6 & 2 & \mathrm{~mm} / \mathrm{day}\end{array}$}

FIG. 10. Projected changes in the leading EOF modes of the interannual variations of the monsoon-year precipitation $\left(\mathrm{mm} \mathrm{day}^{-1}\right)$ for each regional monsoon. Shown are the spatial patterns of the EOF1 mode derived from the historical run and SSP2-4.5 run. The PCC and NRMSE are between the historical experiment and SSP2-4.5 experiment.

changes unlikely account for the differences in the regional monsoon precipitation changes. It can be seen from Fig. 14 that the $850-\mathrm{hPa}$ specific humidity will increase by about $15 \%-20 \%$ by the end of the twenty-first century, implying an increase by about $7 \%$ per degree of global warming following the ClausiusClapeyron equation (Held and Soden 2006). However, the increasing specific humidity in all regional summer monsoon tends to be similar. Therefore, the uniform increasing specific humidity in all regional monsoons cannot explain the markedly different precipitation changes, and the circulation change must be the fundamental causes of the different LMP changes in various regional monsoons (Endo and Kitoh 2014).

\section{b. Mechanisms of future change and sources of uncertainty revealed by the intermodel spread}

Analysis of the intermodel spread can shed physical insights into the mechanisms governing the regional monsoon change and the sources of the projected uncertainty, as demonstrated by Wang et al. (2020b) for the $\mathrm{NH}$ and $\mathrm{SH}$ monsoon precipitation. Here we examine $\mathrm{NH}$ regional monsoon changes through analysis of the intermodel spreads.

Over northern Africa, the models that project a higher increase in NAF land monsoon precipitation correspond to a greater increase in the Saharan and the adjacent North Atlantic surface air temperature with $r=0.68$ ( $p<0.01)$ (Fig. 15a). Thus, the enhanced NAF LMP in the future may be attributed to the Saharan and adjacent North Atlantic warming. The Saharan warming favors an enhanced Sahara low pressure and increases the westerly monsoon. The North Atlantic warming can increase the meridional pressure gradients in the Atlantic Ocean and enhance the northward crossequatorial flows toward northern Africa. The uncertainties in the models' projected North Atlantic SST and Saharan surface air temperature changes may cause the projected uncertainty in the NAF LMP. 
TABLE 3. Definition of the regional summer monsoon circulation indices and their correlation coefficients (CCs) with the corresponding regional summer land monsoon precipitation indices for the period 1979-2014 derived from the observation (GPCP and ERA-Interim). The precipitation indices are defined by the local summer land precipitation averaged over the regions shown in the green shading in Fig. 1. The correlation coefficients were computed using monthly time series (140 summer months) [June-September (JJAS) in the NH (19792013) and December-March (DJFM) in the SH (1979/80-2013/14].

\begin{tabular}{lcc}
\hline \hline Region & \multicolumn{1}{c}{ Definition of the circulation index } & JJAS monthly \\
\hline NAF & $\mathrm{U} 850\left(0^{\circ}-15^{\circ} \mathrm{N}, 30^{\circ} \mathrm{W}-30^{\circ} \mathrm{E}\right)$ & 0.65 \\
SA & $\mathrm{U} 850\left(10^{\circ}-20^{\circ} \mathrm{N}, 40^{\circ}-80^{\circ} \mathrm{E}\right)$ minus U850 $\left(25^{\circ}-32.5^{\circ} \mathrm{N}, 75^{\circ}-90^{\circ} \mathrm{E}\right)$ & 0.63 \\
EA & $\mathrm{V} 850\left(20^{\circ}-45^{\circ} \mathrm{N}, 110^{\circ}-130^{\circ} \mathrm{E}\right)$ & 0.71 \\
WNP & $\mathrm{U} 850\left(5^{\circ}-15^{\circ} \mathrm{N}, 100^{\circ}-130^{\circ} \mathrm{E}\right)$ minus U850 $\left(20^{\circ}-35^{\circ} \mathrm{N}, 110^{\circ}-140^{\circ} \mathrm{E}\right)$ & 0.83 \\
NAM & $\mathrm{U} 850\left(5^{\circ}-15^{\circ} \mathrm{N}, 120^{\circ}-80^{\circ} \mathrm{W}\right)$ minus U850 $\left(20^{\circ}-30^{\circ} \mathrm{N}, 110^{\circ}-80^{\circ} \mathrm{W}\right)$ & 0.71 \\
SAF & $\mathrm{U} 700\left(5^{\circ}-15^{\circ} \mathrm{S}, 10^{\circ}-30^{\circ} \mathrm{E}\right)$ minus U700 $\left(22.5^{\circ}-30^{\circ} \mathrm{S}, 15^{\circ}-35^{\circ} \mathrm{E}\right)$ & 0.63 \\
AUS & $\mathrm{U} 850\left(0^{\circ}-15^{\circ} \mathrm{S}, 90^{\circ}-130^{\circ} \mathrm{E}\right)$ minus U850 $\left(20^{\circ}-30^{\circ} \mathrm{S}, 100^{\circ}-140^{\circ} \mathrm{E}\right)$ & 0.82 \\
SAM & $\mathrm{U} 850\left(5^{\circ}-15^{\circ} \mathrm{S}, 70^{\circ}-40^{\circ} \mathrm{W}\right)$ minus U850 $\left(22.5^{\circ}-30^{\circ} \mathrm{S}, 60^{\circ}-40^{\circ} \mathrm{W}\right)$ & 0.77 \\
\hline
\end{tabular}

Figure $15 \mathrm{~b}$ shows the analysis results for Asian land monsoon (including both the SA and EA), which suggests that the models that project higher increases in Asian land monsoon precipitation correspond to a sharper landocean thermal contrast between the Eurasian continent and adjacent Indian and Pacific Oceans in the Eastern Hemisphere $(r=0.78, p<0.01)$. The results have twofold implications. On the one hand, the multimodel physics suggests that future change of Asian land monsoon precipitation is likely enhanced by the GHG forcing-induced "land warmer than ocean" temperature pattern that strengthens the Asian monsoon circulation (Endo et al. 2018). On the other hand, the intermodel spreads suggest that the uncertainties in the models' projected land-ocean thermal contrast can cause the projected uncertainty in Asian LMP change.

The enhanced land-ocean thermal contrast in the future will favor increasing Asian-North African monsoons but not North American monsoons, where the Central American land bridge is surrounded by vast oceans. Thus, the east-west asymmetry in the NH monsoon response is only partially attributed to the GHG-forced pattern of land warmer than ocean as it does not explain the reduced total precipitation over the NAM. However, we find a linkage between the projected NAM total summer rainfall and the equatorial central Pacific SST with $r=-0.54$ ( $p<0.01$ ) (Fig. 15c). The model with a drier NAM features a warmer equatorial central Pacific, suggesting that projected future warming in the equatorial central Pacific may be responsible for reduced NAM precipitation. Physically, this linkage resembles what happens during an El Niño event (Magaña et al. 2003). The result in Fig. 15c also suggests that the uncertainties in the models' projected equatorial Pacific SST change would induce uncertainty in NAM summer monsoon precipitation.

It is speculated that over South America, Australia, and southern Africa, the effect of the projected increase in local land-ocean thermal contrast is largely offset by the opposing remote effects of the $\mathrm{NH}$ warming more than the $\mathrm{SH}$, so that the $\mathrm{SH}$ regional monsoons show an inhomogeneous summer rainfall pattern and the total LMP tends to be slightly increased.

\section{Conclusions and discussion}

The future changes of land monsoon precipitation are investigated with 24 coupled models that participated in CMIP6. We designed four metrics for evaluation of the models' performance: summer mean precipitation, monsoon intensity, the EOF1 mode of the monsoon-year precipitation, and the standard deviation of summer mean precipitation. The models capture the monsoon rainfall climatology more realistically than its variability (Fig. 2); however, the summer mean rainfall is overproduced in the WNP and shows the largest pattern errors in AUS and SAM. The monsoon intensity is simulated better in four strong monsoon regions (SA, NAF, AUS, and SAF) than in four weak monsoon regions (EA, NAM, SAM, and WNP) (Fig. 3). The interannual variability is commonly overestimated, especially over AUS, SA, SAF, and WNP, where the variances over the ocean and adjacent regions are considerably overestimated (Fig. 4). The spatial patterns of the EOF1 of year-to-year variations are generally realistic except for NAF (Fig. 5). The relationships between ENSO and regional monsoon EOF1 are captured reasonably well for most regional monsoons except for the SA and perhaps NAF monsoons (Table 2). The overall skill scores are relatively low over AUS, NAF, and WNP, mainly due to poorly simulated interannual variability, suggesting the models' common weaknesses in these regions (Fig. 7a). The failure in the simulation of the ENSO-SAM relationship could underestimate the negative impact of the model projected El Niño-like warming on the projected SA LMP. The identified common problems in the simulation of regional monsoons point to the targets for future model improvement.

Under the SSP2-4.5 warming scenario, the CMIP6 models' projected changes of the regional monsoons are summarized as follows.

1) The projected summer mean LMP over SA will very likely increase, and the EA, NAF, and WNP summer rainfall will likely increase, but the NAM LMP will likely decrease (Fig. 8a). The highest summer precipitation sensitivity is seen in EA $\left(4.6 \%{ }^{\circ} \mathrm{C}^{-1}\right)$ and SA $\left(4.1 \%{ }^{\circ} \mathrm{C}^{-1}\right)$. The projected annual mean rainfall changes over $\mathrm{SH}$ monsoon regions (i.e., AUS, SAF, and SAM) are neutral (Fig. 8c). In the NH, the summer precipitation changes dominate the annual 

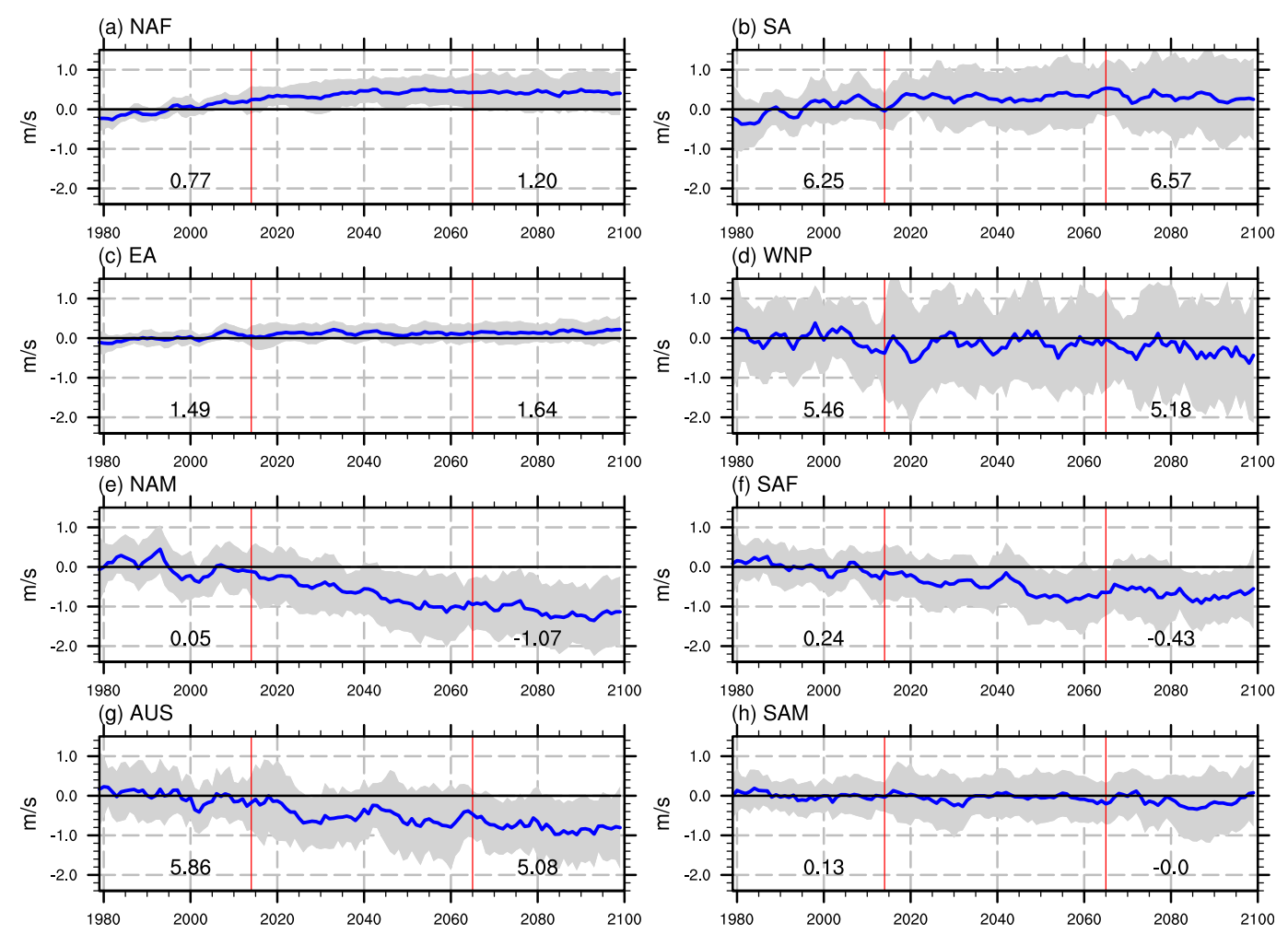

FIG. 11. Present to future change of the summer monsoon circulation indices in eight monsoon regions. The time series are obtained from the CMIP6 24 models' MME for the historical run period (1979-2014) and the SSP2-4.5 run period (2015-2100). The zero line is determined by the present-day (1979-2014) climatology and the time series are the anomalies against the present-day climatology. The MME's uncertainty for mean monsoon circulation is represented by one standard deviation of the individual model's departure from the 24MME. A 5-yr moving averaging was applied to all time series. The two numbers in each panel are the climatological mean over 1979-2014 and 2065-2100, separately.

mean changes, but in the SH the summer and winter precipitation changes are in opposite directions, contributing to the insignificant change in the annual mean precipitation. Note that the SH regional LMP during winter will all be suppressed in the future, which is consistent with the significant increase in the NH summer LMP, suggesting an $\mathrm{NH}-\mathrm{SH}$ linkage thorough the Hadley circulation.

2) The projected interannual variability of the seasonal and annual mean precipitation tends to follow those of the corresponding mean LMP changes except for the NAM; however, these changes are likely insignificant due to large uncertainties. The summer LMP variability will likely increase only over SAF and SAM (Fig. 9).

3) The projected spatial patterns and variance of the leading modes of the monsoon-year precipitation will not change in all regional monsoons (Fig. 10). However, the projected ENSO-regional LMP relationship will be enhanced over SA and perhaps SAF and SAM, but basically unchanged in other regions (Table 2).

4) The projected lower tropospheric summer circulation changes show significant declining trends in NAM, AUS, and SAF and an increasing trend in NAF (Fig. 11). The decreasing (increasing) trends are consistent with the low-level anticyclonic (cyclonic) circulation changes (Fig. 12). The monsoon circulation indices exhibit slightly increasing trends over SA and EA, but they are not statistically significant.

5) The projected summer LMP over the NH regional monsoons (EA, SA, NAF, and NAM) are generally homogeneous (Fig. 12), which is consistent with the corresponding lower tropospheric circulation changes: cyclonic circulation changes in Asia and NAF correspond to increased rainfall, and the anticyclonic circulation change in NAM corresponds to decreased rainfall. However, in SH monsoon regions, the summer rainfall changes tend to show a north-south dipolar pattern (e.g., AUS, SAF, and SAM), which are also consistent with the corresponding circulation change patterns.

What drives the future changes of the regional monsoon precipitation? Our study suggests the following conclusions.

1) Moisture conservation analysis indicates that, in all regional monsoons, the LMP change is dominated by the changes of the vertical moisture advection $[\langle\omega(\partial q / \partial p)\rangle]$. In contrast, the horizontal moisture advection $\left(\left\langle\mathbf{V}_{h} \cdot \nabla q\right\rangle\right)$ is generally negligibly small, and the surface evaporation contributes to a moderate increase (Fig. 13). 

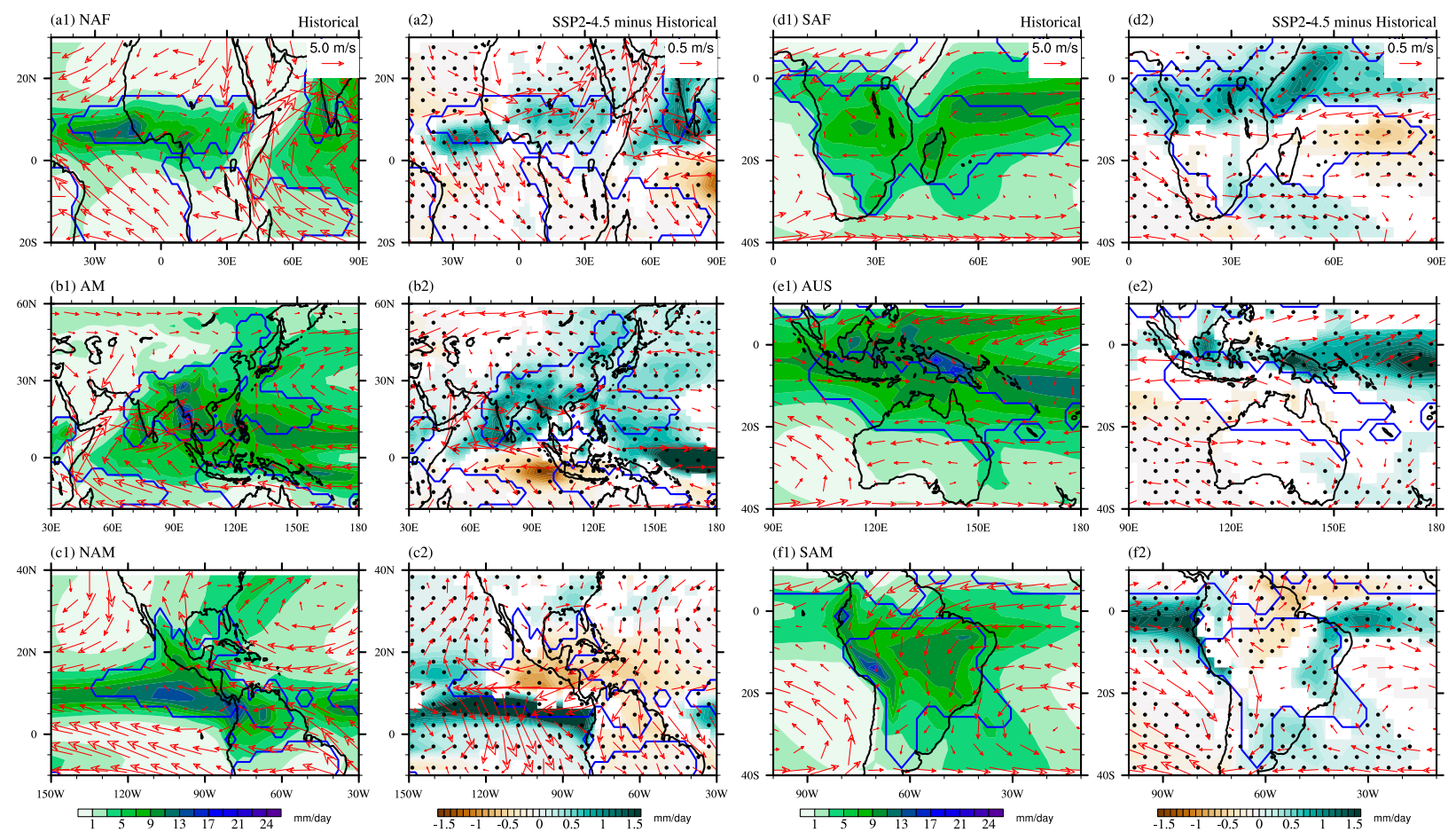

FIG. 12. Spatial patterns of the summer (JJAS in NH and DJFM in SH) 850-hPa winds (vectors; $\mathrm{m} \mathrm{s}^{-1}$ ) and precipitation (shading; $\mathrm{mm} \mathrm{day}^{-1}$ ): (a1)-(f1) Climatological mean in the CMIP6 24MME and (a2)-(f2) future change (2065-2100 relative to 1979-2014). Note that the winds over the SAF region are an exception at $700 \mathrm{hPa}$ to lessen the influence of topography. The shading areas in (a2)-(f2) denote precipitation changes significant at the $66 \%$ confidence level; the stippled areas denote precipitation changes significant at the $95 \%$ confidence level using a two-tailed Student's $t$ test.

2) The regionally averaged summer LMP can be well approximated by the product of upward motion $\left(-\omega_{500}\right)$ and the specific humidity at $850 \mathrm{hPa}\left(q_{850}\right)$ in all regions (Fig. 14). The underestimation in EA is due to the neglect of evaporation, which accounts for a significant contribution (Fig. 13).
3) Specific humidity in all regional monsoons tends to increase at a similar rate of about $7 \%{ }^{\circ} \mathrm{C}^{-1}$ (Fig. 14). Therefore, it cannot explain the regional differences. It is the circulation change that is responsible for the marked differences in the LMP change among various regional monsoons (Fig. 14).

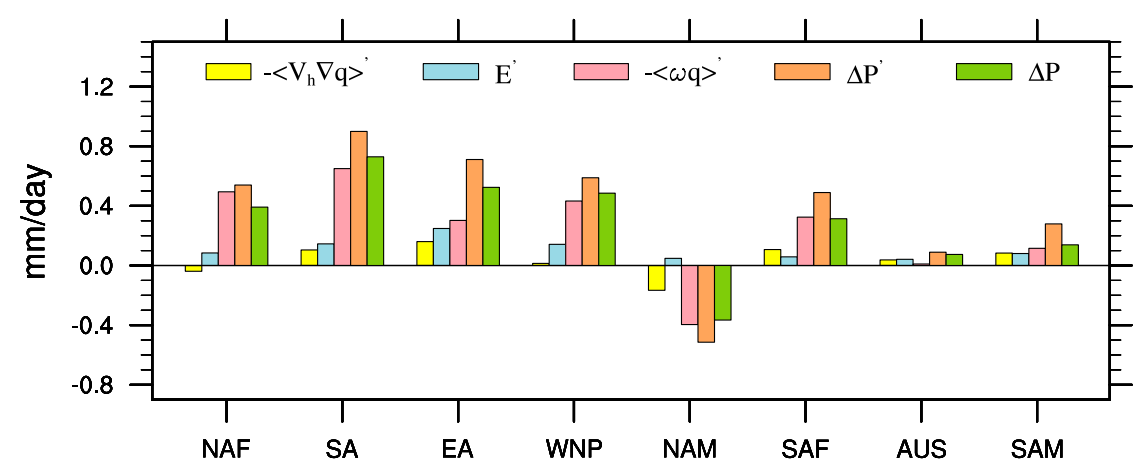

FIG. 13. Moisture budget of the local summer land monsoon precipitation change (the 2065-2100 mean relative to the 1979-2014 mean) in each monsoon region based on the areaaveraged moisture conservation Eq. (5). The change and each component are estimated based on the CMIP6 24MME. Yellow, light blue, light pink, orange, and green bars denote the horizontal moisture advection changes $\left(-\left\langle\mathbf{V}_{h} \cdot \nabla q\right\rangle^{\prime}\right)$, evaporation changes $\left(E^{\prime}\right)$, vertical moisture convergence changes $\left(-\langle\omega q\rangle^{\prime}\right)$, the diagnosed precipitation changes $\left(\Delta P^{\prime}\right)$, and the simulated precipitation changes $(\Delta P)$, respectively; $E$ and $P$ are the surface evaporation and precipitation, $q$ is the 850 -hPa specific humidity, $\mathbf{V}_{h}$ is the $850-\mathrm{hPa}$ wind vectors, and $\omega$ is the 500 -hPa vertical pressure velocity. 

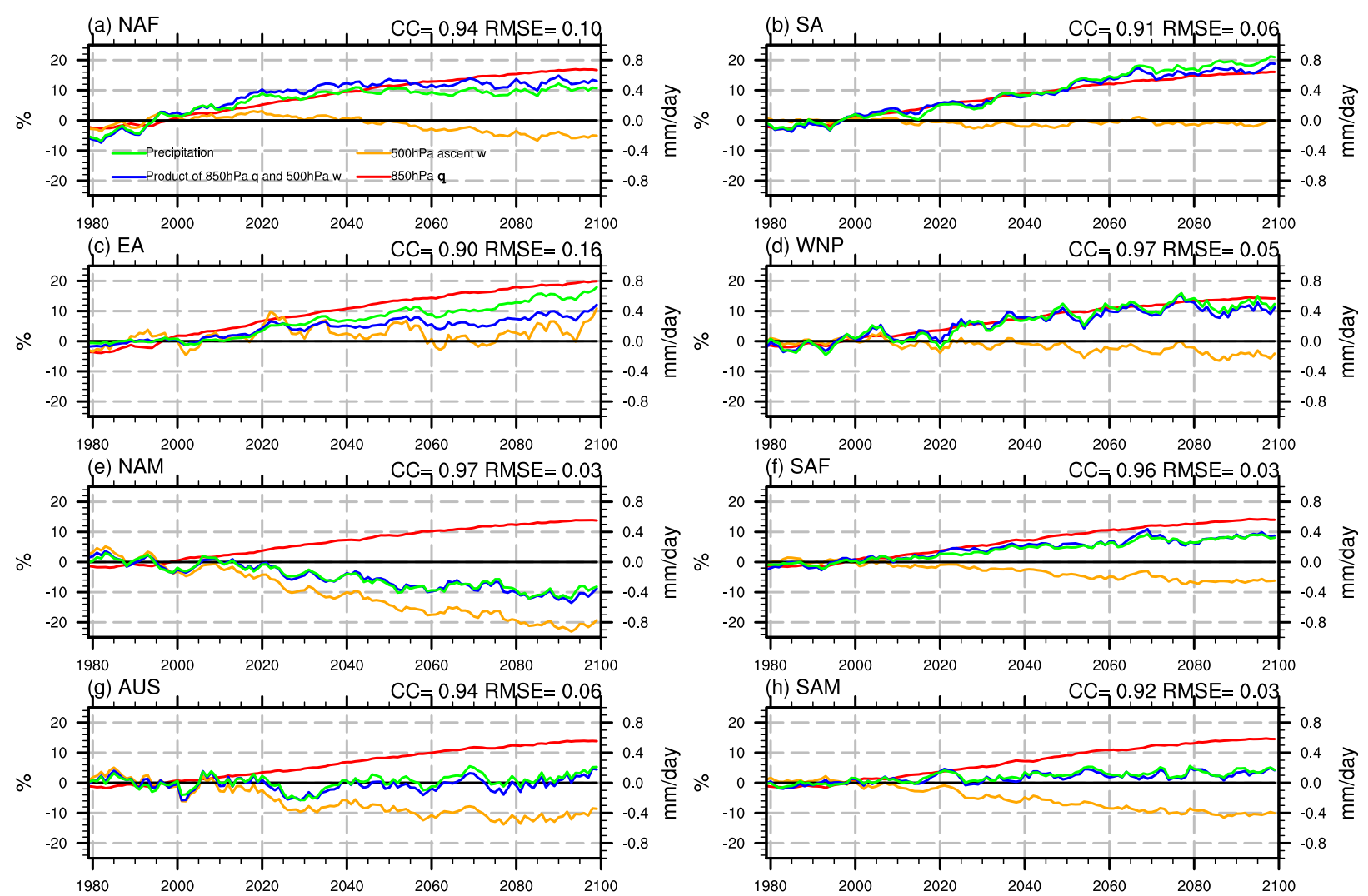

FIG. 14. Transient responses of the $850-\mathrm{hPa} q$ (specific humidity; red lines), 500-hPa ascent $\omega$ (the negative vertical pressure velocity at $500 \mathrm{hPa}$ ), product of $850-\mathrm{hPa} q$ and $500-\mathrm{hPa} \omega$ (the diagnosed precipitation; blue line), and the simulated precipitation (green line) obtained from the 24MME for the historical run period (1979-2014) and the SSP2-4.5 run period (2015-2100) in each regional monsoon. The $q$ and $\omega$ are shown in percentage changes, i.e., the anomalies normalized by its corresponding mean during 1979-2014. The diagnosed and simulated precipitation $\left(\mathrm{mm} \mathrm{day}^{-1}\right)$ are anomalies with reference to their corresponding mean values during 1979-2014. The PCC and RMSE in the top-right corners are between diagnosed and simulated precipitation. A 5-yr moving average was applied to all time series.

4) The intermodel spread analysis offers physical insights into the mechanisms by which the circulation changes lead to the regional monsoon precipitation changes. It is shown that the GHGs forcing-induced "land warmer than ocean" temperature pattern strengthens the Asian monsoon circulation, thus enhances Asian LMP (Fig. 15b). The GHGs forcing-induced "warm Sahara and North Atlantic" pattern may enhance the NAF LMP (Fig. 15a). The future reduction of the NAM total summer rainfall is significantly linked to the models' projected equatorial central Pacific warming (Fig. 15c).

5) The intermodel spread analysis suggests that the models' biases in projected land-sea thermal contrast likely contribute to the models' uncertainties in the projected Asian and North African monsoon rainfall changes, and the biases in projected equatorial Pacific and North Atlantic SST changes may be sources of uncertainties in the projected North American and northern African monsoons.

The present study challenges the conventional view that the greenhouse gas (GHG)-induced thermodynamic effect (increasing moisture) plays a major role in monsoon rainfall change (e.g., Hsu et al. 2013; Seager et al. 2010). We argue that the GHG-induced thermodynamic effects not only increase atmospheric moisture content that tends to increase precipitation, but also stabilize the atmosphere by its top-heavy heating, reducing convection mass flux and precipitation (Chadwick et al. 2016; Bony et al. 2013; Vecchi and Soden 2007). These two aspects of thermodynamic effects tend to offset each other. As demonstrated in Wang et al. (2020b), the GHG radiative forcing induces horizontally nonuniform warming characterized by "NH warmer than SH" and "land warmer than ocean" patterns, as well as tropical SST gradients. Note that in summer monsoon regions, the increased specific humidity and atmospheric static stability are homogeneous across all regional monsoons, suggesting that the thermodynamic effects do not explain the significant different responses of the regional monsoons. It is the response of the coupled climate system to GHG forcing that generates these nonuniform heating distributions, which drives the future changes of the circulation and determines the different response of the regional monsoon precipitation.

Note that the CMIP6 projections for the monsoon change generally agree with the CMIP5 results. However, there are several differences. 1) The monsoon precipitation sensitivities projected by the CMIP6 is systematically lower than the 

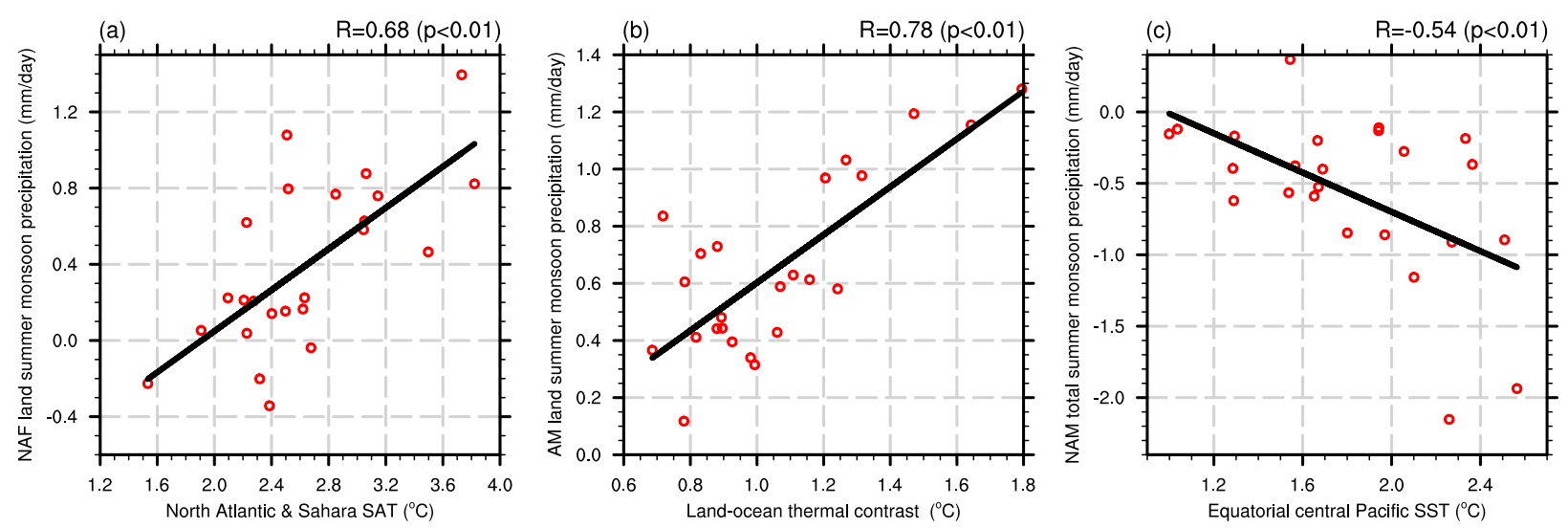

FIG. 15. Results from analysis of the intermodel spread projected by 24 CMIP6 models. (a) The relationship between the JJAS mean NAF land monsoon precipitation and the SAT over the North Atlantic $\left(20^{\circ}-40^{\circ} \mathrm{N}, 60^{\circ} \mathrm{W}-0^{\circ}\right)$ and Sahara $\left(25^{\circ}-35^{\circ} \mathrm{N}, 0^{\circ}-60^{\circ} \mathrm{E}\right)$. (b) The relationship between the JJAS mean Asian monsoon (AM) land precipitation and the land-ocean thermal contrast measured by the surface air temperature difference between the land in the domain $\left(0^{\circ}-60^{\circ} \mathrm{N}, 30^{\circ} \mathrm{E}-180^{\circ}\right)$ and the ocean in the domain $\left(10^{\circ} \mathrm{S}-60^{\circ} \mathrm{N}, 30^{\circ} \mathrm{E}-\right.$ $\left.180^{\circ}\right)$. (c) The relationship between JJAS mean NAM total monsoon precipitation and the equatorial central Pacific $\left(5^{\circ} \mathrm{S}-5^{\circ} \mathrm{N}, 150^{\circ} \mathrm{E}-\right.$ $\left.130^{\circ} \mathrm{W}\right) \mathrm{SST} ; R$ denotes the correlation coefficient.

CMIP5 projection shown by Lee and Wang (2014), but the decrease may not be significant given the large intermodel spread. 2) In the CMIP6 projection, the northern African wetting is stronger and the Venezuelan monsoon drying is weaker than shown in the CMIP5 projections. 3) The CMIP6 projects no change over the northern and southeast Australia, but the CMIP5 model suggests an increase of northern Australian precipitation (Jourdain et al. 2013). 4) The circulation change over the SA monsoon features a slightly increasing trend in CMIP6, which seems different from that projected by the CMIP5 (Wang et al. 2014).

The model bias in simulated mean precipitation and variability can potentially increase the projected uncertainties. The largest bias in the simulated mean precipitation is found over the WNP (Figs. 2 and 3), which has been a well-known weakness of the models since CMIP3 (Sperber et al. 2013). Since mean precipitation sensitivity is a major target of our analysis, we would suggest that the projected WNP rainfall is less reliable given such a poor historical simulation. Biases in the simulated variability could amplify uncertainties in future projections (Wang et al. 2020a). The intermodel spread analysis shows that regional SST and land-ocean thermal contrast have considerable influence on regional LMP projection. For instance, models that project a warm eastern Pacific tend to project a drying NAM (Fig. 15c). Therefore, models' biases in simulated SST could induce uncertainty in the projected surface warming patterns and thus the regional LMP. However, we did not evaluate the models' bias in SST partly because many previous studies have focused on the analysis of SST bias and its impact on future projected SST pattern, including the cold-tongue bias in the tropical eastern Pacific (Chen and Zhou 2015; Ying et al. 2019; Seager et al. 2019) and the cold bias beneath underestimated marine stratocumulus, which can induce a large land-sea thermal contrast in the future (Nam et al. 2012). For details, readers are referred to a recent review paper (Wang et al. 2020a).
Acknowledgments. This work was supported by the National Natural Science Foundation of China (Grants 41420104002, 41971108, 41671197, and 41971021). B.W. acknowledges the support of NSF/Climate Dynamics Award AGS-1540783. J.L. and B.W. are supported by the National Key Research and Development Program of China (Grant 2016YFA0600401). C.-H. J. acknowledges the support from the program of China Scholarships Council (201806860029). This is publication No. 11118 of the School of Ocean and Earth Science and Technology, publication No. 1466 of the International Pacific Research Center, and publication No. 320 of the Earth System Modeling Center.

\section{REFERENCES}

Adler, R. F., and Coauthors, 2003: The version-2 Global Precipitation Climatology Project (GPCP) monthly precipitation analysis (1979present). J. Hydrometeor., 4, 1147-1167, https://doi.org/10.1175/ 1525-7541(2003)004<1147:TVGPCP > 2.0.CO;2.

Ashrit, R. G., A. Kitoh, and S. Yukimoto, 2005: Transient response of ENSO-monsoon teleconnection in MRI-CGCM2.2 climate change simulations. J. Meteor. Soc. Japan, 83, 273-291, https:// doi.org/10.2151/JMSJ.83.273.

Biasutti, M., 2013: Forced Sahel rainfall trends in the CMIP5 archive. J. Geophys. Res. Atmos., 118, 1613-1623, https:// doi.org/10.1002/JGRD.50206.

Bony, S., G. Bellon, D. Klocke, S. Sherwood, S. Fermepin, and S. Denvil, 2013: Robust direct effect of carbon dioxide on tropical circulation and regional precipitation. Nat. Geosci., 6, 447-451, https://doi.org/10.1038/ngeo1799.

Bukovsky, M. S., C. M. Carrillo, D. J. Gochis, D. M. Hammerling, R. R. McCrary, and L. O. Mearns, 2015: Toward assessing NARCCAP regional climate model credibility for the North American monsoon: Future climate simulations. J. Climate, 28, 6707-6728, https://doi.org/10.1175/JCLI-D-14-00695.1.

Cai, W., and Coauthors, 2014: Increasing frequency of extreme El Niño events due to greenhouse warming. Nat. Climate Change, 4, 111-116, https://doi.org/10.1038/nclimate2100. 
Chadwick, R., P. Good, and K. Willett, 2016: A simple moisture advection model of specific humidity change over land in response to SST warming. J. Climate, 29, 7613-7632, https:// doi.org/10.1175/JCLI-D-16-0241.1.

Chen, X., and T. Zhou, 2015: Distinct effects of global mean warming and regional sea surface warming pattern on projected uncertainty in the South Asian summer monsoon. Geophys. Res. Lett., 42, 9433-9439, https://doi.org/10.1002/ 2015 GL066384.

Colorado-Ruiz, G., T. Cavazos, J. A. Salinas, P. De Grau, and R. Ayala, 2018: Climate change projections from Coupled Model Intercomparison Project phase 5 multi-model weighted ensembles for Mexico, the North American monsoon, and the mid-summer drought region. Int. J. Climatol., 38, 5699-5716, https://doi.org/10.1002/joc.5773.

Cook, B. I., and R. Seager, 2013: The response of the North American monsoon to increased greenhouse gas forcing. J. Geophys. Res. Atmos., 118, 1690-1699, https://doi.org/ 10.1002/JGRD.50111.

Dee, D. P., and Coauthors, 2011: The ERA-Interim reanalysis: Configuration and performance of the data assimilation system. Quart. J. Roy. Meteor. Soc., 137, 553-597, https://doi.org/ 10.1002/qj.828.

Duffy, P. B., P. Brando, G. P. Asner, and C. B. Field, 2015: Projections of future meteorological drought and wet periods in the Amazon. Proc. Natl. Acad. Sci. USA, 112, 13 172-13 177, https://doi.org/10.1073/pnas.1421010112.

Endo, H., and A. Kitoh, 2014: Thermodynamic and dynamic effects on regional monsoon rainfall changes in a warmer climate. Geophys. Res. Lett., 41, 1704-1711, https://doi.org/10.1002/ 2013 GL059158.

- - - and H. Ueda, 2018: A unique feature of the Asian summer monsoon response to global warming: The role of different land-sea thermal contrast change between the lower and upper troposphere. SOLA, 14, 57-63, https://doi.org/ 10.2151/SOLA.2018-010.

Eyring, V., S. Bony, G. A. Meehl, C. A. Senior, B. Stevens, R. J. Stouffer, and K. E. Taylor, 2016: Overview of the Coupled Model Intercomparison Project Phase 6 (CMIP6) experimental design and organization. Geosci. Model Dev., 9, 19371958, https://doi.org/10.5194/gmd-9-1937-2016.

Fasullo, J., 2012: A mechanism for land-ocean contrasts in global monsoon trends in a warming climate. Climate Dyn., 39, 11371147, https://doi.org/10.1007/s00382-011-1270-3.

Geil, K. L., Y. L. Serra, and X. Zeng, 2013: Assessment of CMIP5 model simulations of the North American monsoon system. J. Climate, 26, 8787-8801, https://doi.org/10.1175/JCLI-D-1300044.1.

Guo, Q.-Y., 1983: The summer monsoon intensity index in East Asia and its variation. Acta Geogr. Sin., 38, 207-217.

Held, I. M., and B. J. Soden, 2006: Robust responses of the hydrological cycle to global warming. J. Climate, 19, 5686-5699, https://doi.org/10.1175/JCLI3990.1.

Hsu, P., T. Li, H. Murakami, and A. Kitoh, 2013: Future change of the global monsoon revealed from 19 CMIP5 models. J. Geophys. Res. Atmos., 118, 1247-1260, https://doi.org/10.1002/JGRD.50145.

Huang, B., and Coauthors, 2017: Extended Reconstructed Sea Surface Temperature, version 5 (ERSSTv5): Upgrades, validations, and intercomparisons. J. Climate, 30, 8179-8205, https://doi.org/10.1175/JCLI-D-16-0836.1.

Jones, C., and L. M. V. Carvalho, 2013: Climate change in the South American monsoon system: Present climate and CMIP5 projections. J. Climate, 26, 6660-6678, https://doi.org/10.1175/ JCLI-D-12-00412.1.

Jourdain, N. C., A. Sen Gupta, A. S. Taschetto, C. C. Ummenhofer, A. F. Moise, and K. Ashok, 2013: The Indo-Australian monsoon and its relationship to ENSO and IOD in reanalysis data and the CMIP3/CMIP5 simulations. Climate Dyn., 41, 30733102, https://doi.org/10.1007/s00382-013-1676-1.

Kitoh, A., H. Endo, K. Krishna Kumar, I. F. A. Cavalcanti, P. Goswami, and T. Zhou, 2013: Monsoons in a changing world: A regional perspective in a global context. J. Geophys. Res. Atmos., 118, 3053-3065, https://doi.org/10.1002/JGRD.50258.

Lee, J.-Y., and B. Wang, 2014: Future change of global monsoon in the CMIP5. Climate Dyn., 42,101-119, https://doi.org/10.1007/ s00382-012-1564-0.

Magaña, V. O., J. L. Vázquez, J. L. Pérez, and J. B. Pérez, 2003: Impact of El Niño on precipitation in Mexico. Geofis. Int., 42, 313-330.

Malhi, Y., J. T. Roberts, R. A. Betts, T. J. Killeen, W. Li, and C. A. Nobre, 2008: Climate change, deforestation, and the fate of the Amazon. Science, 319, 169-172, https://doi.org/10.1126/ science.1146961.

Mastrandrea, M. D., and Coauthors, 2010: Guidance note for lead authors of the IPCC Fifth Assessment Report on consistent treatment of uncertainties. IPCC, 7 pp., https://www.ipcc.ch/ site/assets/uploads/2018/05/uncertainty-guidance-note.pdf.

Meehl, G. A., and Coauthors, 2007: Global climate projections. Climate Change 2007: The Physical Science Basis, S. Solomon et al., Eds., Cambridge University Press, 747-846.

Menon, A., A. Levermann, J. Schewe, J. Lehmann, and K. Frieler, 2013: Consistent increase in Indian monsoon rainfall and its variability across CMIP-5 models. Earth Syst. Dyn., 4, 287300, https://doi.org/10.5194/esd-4-287-2013.

Meyer, J. D. D., and J. Jin, 2017: The response of future projections of the North American monsoon when combining dynamical downscaling and bias correction of CCSM4 output. Climate Dyn., 49, 433-447, https://doi.org/10.1007/s00382-016-3352-8.

Moon, S., and K.-J. Ha, 2017: Temperature and precipitation in the context of the annual cycle over Asia: Model evaluation and future change. Asia-Pac. J. Atmos. Sci., 53, 229-242, https:// doi.org/10.1007/s13143-017-0024-5.

Nam, C., S. Bony, J. Dufresne, and H. Chepfer, 2012: The 'too few, too bright' tropical low-cloud problem in CMIP5 models. Geophys. Res. Lett., 39, L21801, https://doi.org/10.1029/2012gl053421.

North, G. R., T. L. Bell, R. F. Cahalan, and F. J. Moeng, 1982: Sampling errors in the estimation of empirical orthogonal functions. Mon. Wea. Rev., 110, 699-706, https://doi.org/ 10.1175/1520-0493(1982)110<0699:SEITEO > 2.0.CO;2.

O'Neill, B. C., and Coauthors, 2016: The Scenario Model Intercomparison Project (ScenarioMIP) for CMIP6. Geosci. Model Dev., 9, 34613482, https://doi.org/10.5194/gmd-9-3461-2016.

Pachauri, R. K., and Coauthors, 2014: Climate Change 2014: Synthesis Report. IPCC, 151 pp.,https:/www.ipcc.ch/site/assets/ uploads/2018/05/SYR_AR5_FINAL_full_wcover.pdf.

Pascale, S., W. R. Boos, S. Bordoni, T. L. Delworth, S. B. Kapnick, H. Murakami, G. A. Vecchi, and W. Zhang, 2017: Weakening of the North American monsoon with global warming. Nat. Climate Change, 7, 806-812, https://doi.org/10.1038/nclimate3412.

Ramage, C. S., 1971: Monsoon Meteorology. Academic Press, $296 \mathrm{pp}$.

Rayner, N. A., D. E. Parker, E. B. Horton, C. K. Folland, L. V. Alexander, D. P. Rowell, E. C. Kent, and A. Kaplan, 2003: Global analyses of sea surface temperature, sea ice, and night marine air 
temperature since the late nineteenth century. J. Geophys. Res., 108, 4407, https://doi.org/10.1029/2002JD002670.

Roehrig, R., D. Bouniol, F. Guichard, F. Hourdin, and J.-L. Redelsperger, 2013: The present and future of the West African monsoon: A process-oriented assessment of CMIP5 simulations along the AMMA transect. J. Climate, 26, 64716505, https://doi.org/10.1175/JCLI-D-12-00505.1.

Sabeerali, C. T., and R. S. Ajayamohan, 2018: On the shortening of Indian summer monsoon season in a warming scenario. Climate Dyn., 50, 1609-1624, https://doi.org/10.1007/s00382-017-3709-7.

Seager, R., N. Naik, and G. A. Vecchi, 2010: Thermodynamic and dynamic mechanisms for large-scale changes in the hydrological cycle in response to global warming. J. Climate, $\mathbf{2 3}$, 4651-4668, https://doi.org/10.1175/2010JCLI3655.1.

- M. Cane, N. Henderson, D.-E. Lee, R. Abernathey, and H. Zhang, 2019: Strengthening tropical Pacific zonal sea surface temperature gradient consistent with rising greenhouse gases. Nat. Climate Change, 9, 517-522, https://doi.org/10.1038/s41558-019-0505-x.

Seth, A., M. Rojas, and S. A. Rauscher, 2010: CMIP3 projected changes in the annual cycle of the South American monsoon. Climatic Change, 98, 331-357, https://doi.org/10.1007/s10584009-9736-6.

—, S. A. Rauscher, M. Biasutti, A. Giannini, S. J. Camargo, and M. Rojas, 2013: CMIP5 projected changes in the annual cycle of precipitation in monsoon regions. J. Climate, 26, 7328-7351, https://doi.org/10.1175/JCLI-D-12-00726.1.

Sharmila, S., S. Joseph, A. K. Sahai, S. Abhilash, and R. Chattopadhyay, 2015: Future projection of Indian summer monsoon variability under climate change scenario: An assessment from CMIP5 climate models. Global Planet. Change, 124, 62-78, https://doi.org/10.1016/ j.gloplacha.2014.11.004.

Song, F., T. Zhou, and Y. Qian, 2014: Responses of East Asian summer monsoon to natural and anthropogenic forcings in the 17 latest CMIP5 models. Geophys. Res. Lett., 41, 596-603, https://doi.org/10.1002/2013GL058705.

Sperber, K. R., H. Annamalai, I.-S. Kang, A. Kitoh, A. Moise, A. Turner, B. Wang, and T. Zhou, 2013: The Asian summer monsoon: An intercomparison of CMIP5 vs. CMIP3 simulations of the late 20th century. Climate Dyn., 41, 2711-2744, https://doi.org/10.1007/s00382-012-1607-6.

Vecchi, G. A., and B. J. Soden, 2007: Global warming and the weakening of the tropical circulation. J. Climate, 20, 43164340, https://doi.org/10.1175/JCLI4258.1.

Wang, B., 1994: Climatic regimes of tropical convection and rainfall. J. Climate, 7, 1109-1118, https://doi.org/10.1175/15200442(1994)007<1109:CROTCA > 2.0.CO;2.
— annual variation in the tropics. Dyn. Atmos. Oceans, 44, 165183, https://doi.org/10.1016/j.dynatmoce.2007.05.002.

- S. C. Clemens, and P. Liu, 2003: Contrasting the Indian and East Asian monsoons: Implications on geologic timescales. Mar. Geol., 201, 5-21, https://doi.org/10.1016/S0025-3227(03) 00196-8.

_ J. Liu, H.-J. Kim, P. J. Webster, and S.-Y. Yim, 2012: Recent change of the global monsoon precipitation (1979-2008). Climate Dyn., 39, 1123-1135, https://doi.org/10.1007/s00382011-1266-Z.

_ - S.-Y. Yim, J.-Y. Lee, J. Liu, and K.-J. Ha, 2014: Future change of Asian-Australian monsoon under RCP 4.5 anthropogenic warming scenario. Climate Dyn., 42, 83-100, https:// doi.org/10.1007/s00382-013-1769-x.

_, X. Luo, Y.-M. Yang, W. Sun, M. A. Cane, W. Cai, S.-W. Yeh, and J. Liu, 2019: Historical change of El Niño properties sheds light on future changes of extreme El Niño. Proc. Natl. Acad. Sci. USA, 116, 22 512-22 517, https://doi.org/10.1073/pnas.1911130116.

_ , and Coauthors, 2020a: Monsoons climate change assessment. Bull. Amer. Meteor. Soc., https://doi.org/10.1175/BAMS-D19-0335.1, in press.

_ C. Jin, and J. Liu, 2020b: Understanding future change of global monsoons projected by CMIP6 models. J. Climate, $\mathbf{3 3}$, 6471-6489, https://doi.org/10.1175/JCLI-D-19-0993.1.

Webster, P. J., A. M. Moore, J. P. Loschnigg, and R. R. Leben, 1999: Coupled ocean-atmosphere dynamics in the Indian Ocean during 1997-98. Nature, 401, 356-360, https://doi.org/ $10.1038 / 43848$.

Yasunari, T., 1991: The monsoon year-A new concept of the climatic year in the tropics. Bull. Amer. Meteor. Soc., 72, 1331-1338, https:// doi.org/10.1175/1520-0477(1991)072<1331:TMYNCO >2.0.CO;2.

Yim, S.-Y., B. Wang, J. Liu, and Z. Wu, 2014: A comparison of regional monsoon variability using monsoon indices. Climate Dyn., 43, 1423-1437, https://doi.org/10.1007/s00382-0131956-9.

Yin, L., R. Fu, E. Shevliakova, and R. E. Dickinson, 2013: How well can CMIP5 simulate precipitation and its controlling processes over tropical South America? Climate Dyn., 41, 3127-3143, https://doi.org/10.1007/s00382-012-1582-y.

Ying, J., P. Huang, T. Lian, and H. Tan, 2019: Understanding the effect of an excessive cold tongue bias on projecting the tropical Pacific SST warming pattern in CMIP5 models. Climate Dyn., 52, 1805-1818, https://doi.org/10.1007/s00382018-4219-y. 